\title{
Different business models - different users? Uncovering the motives and characteristics of business-to-consumer and peer-to- peer carsharing adopters in The Netherlands
}

\author{
Karla Münzel*, Laura Piscicelli, Wouter Boon, Koen Frenken \\ Innovation Studies Group, Copernicus Institute of Sustainable Development, Utrecht University, Princetonlaan $8 a, 3584$ CB Utrecht, the Netherlands
}

\section{A R T I C L E I N F O}

\section{Keywords:}

Carsharing

Sharing economy

Business-to-consumer

Peer-to-peer

Innovation adoption

Two-sided platform

\begin{abstract}
A B S T R A C T
Carsharing is regarded to play an important part in the transition towards a more sustainable mobility system by changing how cars are used and transportation needs are met. Carsharing adopters own less cars, ride less car kilometers and depend on multiple transportation modes for their travel needs. There has been considerable interest in understanding the characteristics and motives of carsharing adopters. Yet, studies have been mostly limited to small-scale surveys, covering only specific cities or organizations and focusing on traditional $\mathrm{B} 2 \mathrm{C}$ carsharing, disregarding the growing popularity of P2P carsharing through online platforms. This study contributes to extant research by investigating whether characteristics and motives differ between B2C and P2P carsharing adopters, and broadening the scope of the analysis to include an entire country (The Netherlands) and different carsharing provider types. First, our findings suggest that B2C and P2P carsharing adopters are rather similar in their characteristics but differ in the frequency in which they make use of carsharing and public transport. Second, we provide novel insights into the characteristics that influence a car owner to become an adopter of P2P carsharing as a provider. We find that car owners who already shared their car informally outside an online platform are also much more likely to provide their car through an online platform. We conclude with describing policy implications of our findings. Regulation should focus on shaping favorable conditions for a connected multi-modal transportation system instead of specific regulations for each carsharing business model.
\end{abstract}

\section{Introduction}

Next to other innovations like electric vehicles and automated vehicles, carsharing is regarded as an important part of the transition towards a sustainable mobility system (Sperling, 2018). The increasing diffusion of carsharing in recent years is supported by technological innovations like smart keys, GPS services, as well as the widespread use of smartphones (Shaheen et al., 2016b). However, carsharing is still a niche phenomenon. Even though carsharing has already existed for more than twenty years in many Western countries, its current users can still be considered early adopters. In The Netherlands, for example, roughly one percent of adults participate in some form of carsharing (Jorritsma et al., 2015). One of the main challenges remains to attract mainstream consumers to adopt carsharing services and change their mobility behavior. While the economic gains of access instead of ownership of an expensive, non-continuously used asset like a car are clear for people with limited car-dependence, car ownership is

\footnotetext{
* Corresponding author.

E-mail addresses: k.l.munzel@uu.nl (K. Münzel), 1.piscicelli@uu.nl (L. Piscicelli),w.p.c.boon@uu.nl (W. Boon), k.frenken@uu.nl (K. Frenken).
} 
nevertheless deeply entrenched in our societies. Gaining insights into the characteristics and motives of adopters and non-adopters of carsharing is, thus, important for policymakers and businesses alike to support the wider diffusion of carsharing.

Another issue that needs to be considered when analyzing carsharing adoption is the environmental impact of carsharing. Even though we do not directly analyze the impact of carsharing in this study, we discuss implications of our findings also in the light of the environmental effects of carsharing adoption and use. Studies show that carsharing overall holds the promises to have positive impacts on the sustainability of the mobility system through, for example, reducing the numbers of cars owned, car kilometers driven, offering less pollutant cars and incentivizing modal shifts towards public transit and active modes (e.g. walking, cycling) (Chen and Kockelman, 2016; Giesel and Nobis, 2016; Nijland and van Meerkerk, 2017; Schreier et al., 2018). Nonetheless, attention has to be given to possible rebound effects and the differential effects of different forms of carsharing, of different groups of adopters and in different environments.

Extant research on carsharing users is quite extensive, but surveys are usually based on small sample sizes covering only a single city. The large majority of studies is also limited in its exclusive focus on Business-to-Consumer (B2C) carsharing. In the B2C model, also referred to as 'classic carsharing', a carsharing organization owns a fleet of cars that are rented out to users. Yet, the Peer-to-Peer (P2P) service model has recently gained traction, in which consumers rent out their own cars to other consumers through a two-sided platform operated by a coordinating carsharing organization (Shaheen et al., 2016a). ${ }^{1}$ In addition to the fast growth in P2P carsharing, we also witness the progressive blurring of $\mathrm{B} 2 \mathrm{C}$ and $\mathrm{P} 2 \mathrm{P}$ business models and the emergence of new hybrid forms of carsharing facilitated by online platforms that offer both privately-owned and business-owned cars (Frenken, 2017).

Taking the focus of previous studies on B2C carsharing, we do not yet understand whether the adopters of the different types of carsharing differ in their characteristics and motivations. The recent diffusion of P2P carsharing in which car owners act as providers of shared cars also calls for more research into the characteristics and motives of P2P car providers and how this novel practice compares to sharing a car informally (i.e. outside an online platform) with friends and family. Our study thus contributes to the study of two-sided platforms in the mobility sphere where users play a role as suppliers as well as consumers, and it provides new insights on whether users of B2C and P2P carsharing may differ in their characteristics and motives for carsharing.

We analyze a unique dataset stemming from a survey of 1836 Dutch citizens with some having adopted carsharing, some having a self-stated interest to adopt carsharing in the next year, and some showing no interest in adopting carsharing. The database includes socio-demographics, modes of transport and car ownership data, as well as variables on motivations and barriers for carsharing and attitudes towards it. The database includes the adopters of both B2C and P2P carsharing and covers the whole of The Netherlands. We analyze characteristics and motives of adopters, those that declare an intent to adopt, and those not interested to adopt. We further look into the frequency of use among carsharing users. Regarding P2P carsharing specifically, we also investigate characteristics of car owners who act as car providers on a P2P carsharing platform, car owners that declare an intent to make their car available to others online in the near future, and car owners not-interested in sharing their car through a platform.

We will proceed as follows. The next section provides a literature review on carsharing adopter characteristics and motives (Section 2). This is followed by the method section (Section 3) and the results section (Section 4). The paper ends with a discussion of the key findings and some concluding remarks (Section 5). We reflect on the results of our analyses in the light of innovation adoption theory and findings of previous studies about carsharing users and usage. We discuss possible policy recommendations and possible future research avenues following from our findings.

\section{Literature review}

In our study we used a survey dataset in order to analyze carsharing adopters. Prior to the analysis, a literature review is conducted to identify possible independent variables to be included in the analysis. For this, studies that report characteristics of carsharing adopters and factors influencing carsharing adoption were reviewed.

In this section we first detail a brief history of carsharing, especially focusing on the country of our study: the Netherlands. Then, we present an overview of the characteristics of carsharing adopters and the factors influencing carsharing adoption.

\subsection{Brief history of carsharing}

Carsharing is a system that allows people to use locally available cars at any time and for any duration (Frenken, 2015). Early experiments were set up in different European countries, e.g. in Switzerland (1948, 'Sefage'), France (1972, 'Procotip') and the Netherlands (1973, 'Witkar') but failed to operate successfully and were suspended (Shaheen and Cohen, 2007). Successful carsharing initiatives started in the late 1980s in Switzerland and Germany and were at first organized in small projects of environmentallyminded groups (Shaheen et al., 1998). In Europe carsharing has seen a continuous, yet slow growth and geographical diffusion in the 1990s and early 2000s, but only more recently new forms of carsharing have brought a significant rise in carsharing supply and user numbers. The first entrants in the carsharing market organized carsharing in a B2C form, in which the organization (be it for-profit or not-for-profit) owns a fleet of cars that the customers can use. The cars are spread out over a city or city area and users are able to pick up the cars in a self-service fashion and pay by minute, hour or day and distance traveled. Insurances, maintenance and repairs are typically paid for by the carsharing organization. The B2C carsharing forms were initially all based on a roundtrip (RT) mode in which cars have to be returned at the end of the trip to the same spot they were rented from. In 2008 a new form of B2C carsharing,

\footnotetext{
${ }^{1}$ Section 2.1 offers a more in-depth description of the B2C and P2P carsharing forms.
} 
free-floating (FF) carsharing, was introduced that allowed the car to be dropped off anywhere in a designated operation area (Daimler, 2008). Users can locate the car closest to them by means of smartphone technology (Ehrenhard et al., 2017) and car use is mostly limited to short inner-city trips (Martin and Shaheen, 2016). Around 2010, another form of organized carsharing appeared: P2P carsharing. Here, the carsharing organization provides a platform where private car owners and users can be matched and additional services like insurances are offered (Shaheen et al., 2012). P2P carsharing is facilitated by two-sided platforms where private individuals act both as suppliers and consumers. Some people take on both roles, while others act as either suppliers or consumers. P2P carsharing can be easily offered in any region, while B2C carsharing is only offered where usage density is high enough to make providing a car there profitable (Münzel et al., 2018).

\section{Carsharing in the Netherlands}

Carsharing in the Netherlands started with the pioneering 'Witkar' ('white car') experiment in 1973 in Amsterdam. The experiment did not prove successful and was ultimately stopped in 1988. In the 1990s carsharing slowly grew and was stimulated by governmental organizations for the environmental advantages it promised (Nijland and van Meerkerk, 2017). Since then expectations around carsharing have been high, but even today it still has to be seen as a niche market. In 2015 a Green Deal between governmental authorities, companies and environmental organizations was set up with the aim to stimulate carsharing and reach 100,000 carsharing cars by 2018 (Rijksoverheid, 2015) and was renewed in 2018 with the ambition to reach 700,000 carsharing users by 2021 (Rijksoverheid, 2018). In early 2018 there were approximately 41,000 shared cars and 400,000 users in the Netherlands, with a growth of 10,000 in the number of shared cars compared to a year before. The increase is mainly happening in the four largest cities (so called G4 cities: Amsterdam, Rotterdam, The Hague, and Utrecht). The fastest growth is taking place on P2P platforms, which supply 81 percent of shared cars (CROW, 2018). Cars on P2P platforms in the Netherlands are used less frequently than B2C cars, and providers are not usually making an income from renting out their car (Autodelen.info, n.d.). Key exchanges between providers and users are required and smart lock technologies are only slowly being rolled out with the aim to increase convenience (SnappCar, 2018). Another recent development holds that on some platforms both privately owned and company-owned cars are being offered, blurring the boundaries between B2C and P2P business models. The current situation is typical for the state of the carsharing market in Western Europe but different to, for example, the North American market, where carsharing is offered only in larger cities or specific communities (e.g. college campuses), P2P carsharing is already more professionalized thanks to the implementation of digital technologies (e.g. smart locks), and the usage of the cars is much more frequent.

\subsection{Characteristics of carsharing adopters}

Early adopters of a novel service are of particular interest since they can be decisive for the successful diffusion of such innovation. The widely applied study by Rogers (2003, p. 283) characterizes 'early adopters', the second of his adopter categories after the 'innovators', as "typically younger in age, having a higher social status, more financial lucidity, advanced education, and being more socially forward than late adopters". Rogers' (2003) categorization of adopters aids the understanding of human behavior in relation to innovativeness and can, thus, help identify differences in characteristics and motivations of carsharing adopters, as well as provide insights about potential adopter groups. The further transition of an innovation from being used by the early adopters to scaling to an early majority is particularly difficult. Moore (1991) describes that 'crossing this chasm' is crucial for innovations to become widespread.

Extant research on carsharing adoption and carsharing users can be divided into early studies focusing on stated preferences regarding people's intention to adopt carsharing in the future, and a more recent wave of revealed preference studies of actual carsharing adopters. We limit our overview of existing literature to revealed preference studies or studies that combine stated and revealed preference as these provide more reliable insights into carsharing adoption compared to stated preference studies. Our own study focuses on actual adopters as well, although we also compare them to respondents who have the intention to adopt carsharing in the coming year and non-adopters. Relevant literature was found by searching for scientific articles and reports in Google Scholar using the keywords "carsharing" + "adopters/adoption/users" as well as "carsharing" + "motives/reasons to adopt". Furthermore, we specifically searched for studies using multivariate analyses identifying explanatory variables of carsharing adoption inside of the gathered set of articles as well as with the keywords "carsharing" + "multivariate/regression analysis". Additional studies were identified by snowballing from the reference lists of relevant articles. We were able to identify 33 articles describing characteristics of carsharing adopters and/or motives for adoption and nine articles using some kind of multivariate analysis identifying factors that influence the adoption of carsharing or frequency of use.

The studies we found seem to indicate that socio-demographic characteristics of adopters are consistent with the typical character traits of Rogers' early adopters (e.g. Burkhardt and Millard-Ball 2006; Wappelhorst et al. 2013; Kawgan-Kagan 2015). Socio-demographic characteristics, as well as motives to adopt carsharing, are often only briefly described, without analyzing the influence they have on adoption. It also needs to be noted that many of the studies reporting on user attributes surveyed specific services or specific locations, usually focus on one type of carsharing, and range in sample size. Their results on the characterization of carsharing adopters can, thus, not all be directly compared and need to be interpreted with caution. Our literature review, which summarizes the findings of these studies, is concisely presented below. The table in Appendix A lists all included studies and their scope, and can be checked for references and the detailed findings of each study.

\section{B2C carsharing users - typical early adopters}

In line with theory on early adopters of innovations, B2C carshare users tend to be younger than average and more often male. 
Their education and income are generally reported to be high. Findings concerning the household size of the typical carshare adopter are less conclusive. While it is often stated that especially single or small households profit from the cost-efficient opportunity to use a shared car, also families in larger households can choose carsharing as a way to ease the tight budgeting. Understandably, private car ownership is typically lower in the households of carsharing adopters. Additionally, carsharing is often described as diffusing best in areas with high population density.

\section{Motives for carsharing}

Findings on the motives of consumers to start carsharing suggest that, often, the main reasons to join carsharing are cost-savings and increased convenience: time-saving compared to using public transport, an additional transportation mode, gaining freedom, the infrequent need of a car or a large car in case of transporting bulky items. Even though environmentalism and sustainability are often marketed as the advantage of carsharing, these are generally not the primary reason to join a carsharing organization according to the reviewed studies. While a few earlier studies found environmental aspects to be quite high on the motivation list of carsharing members, these motivations seem to have lost ground to financial and convenience motivations over the years. Finally, joining carsharing can be motivated by changes in personal circumstances (e.g. moving to a new house, starting a family or a new job), which may trigger a change in people's habits.

\section{Adopters of P2P carsharing}

Despite the abundance of information about B2C carsharing users and their characteristics, little is known about the adopters (users and providers) of two-sided P2P carsharing platforms. P2P carsharing has been introduced on the market only recently but has grown tremendously. The service offered differs for the users of the shared cars as compared to B2C models on, for example, booking procedure and car access, but more importantly, a second adopter side is added - the car provider. The group of car owners willing to share their car might differ largely from the car user adopters and they likely have different motives to adopt carsharing. Wilhelms et al. (2017a,b), Dill et al. (2017) and Shaheen et al. (2018) have studied the providers and users of P2P carsharing in Germany, Portland (US) and across the US, respectively. All three studies draw a similar picture of the characteristics of P2P carsharing adopters compared to studies on B2C carsharing. P2P adopters are found to be younger and highly educated compared to the general population. Also the income is reported to be generally higher, only users are described to have slightly lower incomes in one case. Next to the users, also providers of cars are described as owning fewer cars and being more positive towards active modes of transport as walking and cycling, and public transport. The motives of users are similar to the findings of studies on B2C carsharing - they are motivated by saving money and time, as well as convenience and mobility gains. Additionally, an interest in the concept of sharing and supporting the local community are mentioned as motives. Providers were found to be motivated by cost savings and the possibility to increase their disposable income, but also by the joy to provide a mobility option to others, facilitating experiences by providing special cars, and an interest in sustainability. Concerns for providers seem to lie in the fear of damage to the car, too low demand and too large hassles that are not outweighed by the gains. Users are hindered in the usage by availability issues and the distance to the vehicles. Other research only explored perceptions of the general population towards P2P. For example, Ballús-Armet et al. (2014) surveyed people in California and found that respondents considered convenience and availability as the main attractions of becoming renters, as well as economic benefits. A quarter of respondents considered renting out their vehicle but were concerned of liability issues, as well as convenience and availability.

\subsection{Factors influencing carsharing adoption}

In addition to descriptive characterizations of carsharing adopters and their motives, it is of great importance to identify the variables that actually influence carsharing adoption using multivariate analysis. The findings presented in Section 2.2 only provide descriptive statistics about carsharing adopters without analyzing which variables actually have an effect on the likelihood of being an adopter in a multivariate setting, i.e. while controlling for other factors. Table 1 provides an overview of multivariate studies that have analyzed in different settings which socio-demographic variables influence carsharing adoption (or membership duration, or use frequency). Again, we exclude studies that are based solely on intentions from our review.

Age is found to significantly influence the likelihood of someone adopting carsharing, stating that younger age positively or older age negatively influences adoption. Gender is identified as an influencing variable in some studies, namely being male is generally stated to have a positive influence on adoption. Often a higher level of education as well as a higher income are found to have a significant positive effect on carsharing adoption. Household size is identified to be of significant influence in a few studies, but with mixed results. Most studies state that living alone or in small households positively influences adoption. The influence of car ownership and the number of cars in a household seems clear: living without a car or owning fewer cars positively influences carsharing adoption or the intention to do so.

A few studies include attitudes in the analysis and identify an environmental concern, a dissatisfaction with transport availability, an orientation towards public transport and perceptions of financial saving possibilities to have a positive influence on adoption.

The review of existing literature on the profile and motives of carsharing adopters reveals that most research has focused on only one business model and carsharing provider (B2C mostly) and/or one geographical area (often a single city). A comparison of different carsharing types and the analysis of a large geographical area including urban and more rural regions are missing. A notable exception is the research by Prieto et al. (2017), which examined the adoption intentions of B2C and P2P carsharing. Although their study does not include data on actual adopters, it provides some valuable insights: P2P carsharing appears to be favorable to a larger range of consumers, it is believed to offer an easier and more flexible service and can, thus, be more attractive than B2C carsharing. 


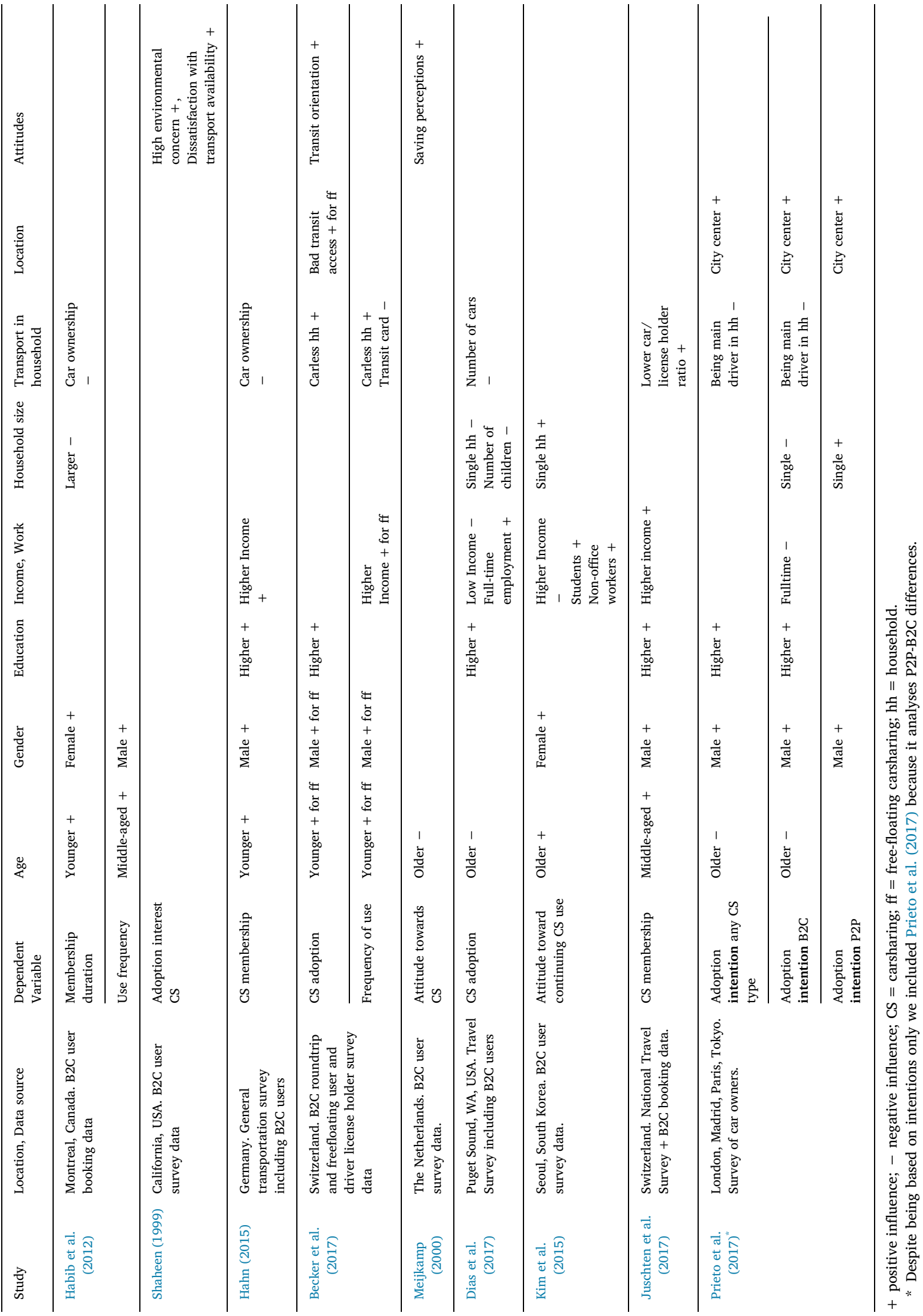


Our study extends Prieto et al.'s (2017) research by studying actual carsharing adopters of multiple business models in a large geographical area.

In summary, existing literature describes carsharing adopters as typical early adopters, young, highly educated urbanites, and finds cost and convenience to be the strongest motives to use carsharing. We therefore include similar variables in our analysis, which are explained in detail in Section 3. We refer back to the findings of previous research when presenting our results, although research questions, survey and respondent types are different and results, thus, do not allow us to draw direct comparisons.

\section{Methodology}

In our study, we make use of a survey dataset collected by the Dutch Institute for Public Opinion and Market Research (TNS-NIPO) in 2014. TNS-NIPO accessed a panel of about 140,000 people representative of the Dutch population and used a pre-screening to all people over the age of 18 to be able to over-sample on actual carsharing adopters. The dataset excluding carsharing adopters is thus representative for the Dutch population over the age of 18 , but the subpopulation of car owners and carsharing adopters was not checked for representativeness. The survey was answered by 1835 participants of which 238 respondents are users of at least one form of organized carsharing, 200 participants stated that they are planning to start carsharing as users in the next 12 months, while the rest showed no interest in doing so. The survey includes 151 B2C carsharing users, 87 P2P carsharing users and another 46 respondents that use both. ${ }^{2}$ When regarding the provider side in $\mathrm{P} 2 \mathrm{P}$ carsharing, the database includes 42 cases of respondents providing cars on a P2P carsharing platform, 149 respondents stated to plan providing a car on a P2P carsharing platform in the next 12 months, while 1298 respondents who owned a car did not show an interest to adopt carsharing as a car provider. Interesting to add is that 523 participants stated that they do lend out their car in a private informal manner to family and friends.

Socio-demographics, attitudes, and motivations of the respondents are analyzed and descriptive results are reported for the adopters of each carsharing forms, as well as for potential adopters and non-adopters. Furthermore, logistic regression analyses are performed to identify which variable influences the chance to be part of one group over another group while controlling for the other variables. Since the dependent variables are categorical variables, logistic regression analyses (instead of, for example, simple linear regression analyses) have to be used to identify which independent variables influence belonging to one of the categories over the other (e.g. carsharing types).

Six analyses are carried out to identify influencing variables for the groups of carsharing adopters versus non-adopters; potential carsharing adopters versus not interested non-adopters; frequent versus infrequent users; P2P versus B2C users; P2P car provider adopters versus non-adopters; and potential provider adopters versus not-interested non-adopters (see Table 2). The assumptions of logistic regressions hold as each respondent is uniquely assigned to a group. The data were also checked for multicollinearity and no issues were identified. Correlation tables, as well as descriptive statistics for the datasets of the four analyses, can be found in Appendix B. Regarding the sample size, the general guideline of a minimum of 10 cases with the least frequent outcome category for each independent variable in the model is considered. We discuss this in more detail in the result section. In addition to logistic regression analyses, ANOVA analyses were conducted to compare the groups as a robustness check and the results revealed similar relationships.

\section{The independent variables}

Based on the earlier findings on adopters of carsharing presented in the literature review (Section 2) and considering the data availability of the survey database, variables were chosen to be included in the logistic regression analyses. Socio-demographic variables that have been identified as being influential for carsharing adoption and were thus included in our analyses are age, gender, education and income. From the findings of earlier studies it is expected that younger age, being male and having a high income and education level positively influence the carsharing adoption likelihood and use frequency. Data on education and income were collected on 8 and 27 levels respectively, but are considered to be metrical in the regression analyses. Results on the influence of household size and family composition in prior research have been mixed; therefore, we included a dummy variable if children under the age of 18 lived in the household. This variable is highly correlated to the variable household size, which is thus not included in our analysis. Furthermore, neighborhood density was found to influence carsharing adoption, so we include a dummy variable covering whether the respondent lives in one of the four largest cities of the Netherlands indicated as 'G4 cities'. The population density in these cities is much higher, as are residential parking fees, and urban policies to reduce car ownership and incentivize carsharing are more ambitious compared to smaller cities and the rest of the country. A positive influence from this variable on carsharing adoption can thus be expected.

Many studies have identified the influence of the set of transportation options someone has access to on carsharing adoption and we therefore include a dummy variable on the ownership of a public transport subscription and a dummy variable if there is no car available in the household, which we expect to both positively influence carsharing adoption. The question on the public transport subscription included in the survey was rather open and the subscriptions could range from discounted travel options in certain hours of the day or on a particular route to unlimited travel in the entire country at all times. Nonetheless, the variable can be used as an indicator of a respondent's regular use of public transport.

\footnotetext{
${ }^{2}$ In the analysis, the 46 respondents using both B2C and P2P carsharing services are categorized according to which type they use more frequently. 20 respondents that use the two services with equal frequency are excluded in regression analysis 3 .
} 
Table 2

The dependent variables and case numbers (total number of respondents $\mathrm{N}=1835$ ).

\begin{tabular}{|c|c|c|c|}
\hline Analysis & Analyses of groups & Categories & $N$ \\
\hline \multirow[t]{2}{*}{1.1} & Adoption as user & Adopter of B2C and/or P2P carsharing as a user & 238 \\
\hline & & Non-adopter of carsharing as a user & 1597 \\
\hline \multirow[t]{2}{*}{1.2} & Potential adoption as user & Potential adopter of carsharing as a user (interested to begin carsharing in the next 12 month) & 200 \\
\hline & & Not interested in adopting carsharing as a user (not interested to begin carsharing in the next 12 months) & 1397 \\
\hline \multirow[t]{2}{*}{2} & Frequency of use & Frequent carsharing users (more than five times per year) & 113 \\
\hline & & Infrequent carsharing users (five times per year or less) & 125 \\
\hline \multirow[t]{2}{*}{3} & Carsharing type & User of B2C carsharing & 168 \\
\hline & & User of P2P carsharing & 50 \\
\hline \multirow[t]{2}{*}{4.1} & Adoption as car provider & Provider of his/her car on a P2P carsharing platform & 42 \\
\hline & & Non-adopter of carsharing provision & 1447 \\
\hline \multirow[t]{2}{*}{4.2} & $\begin{array}{l}\text { Potential adoption as car } \\
\text { provider }\end{array}$ & $\begin{array}{l}\text { Potential provider of his/her car (interested to begin providing a car on a P2P carsharing platform in the } \\
\text { next } 12 \text { months) }\end{array}$ & 149 \\
\hline & & $\begin{array}{l}\text { Non-adopter of carsharing provision (car owner, but not interested to begin providing a car on a P2P } \\
\text { carsharing platform in the next } 12 \text { months) }\end{array}$ & 1298 \\
\hline
\end{tabular}

A few studies mentioned in the literature review identify certain attitudes to influence carsharing adoption. A positive attitude has been related to a pro-environmental mindset. We therefore analyze this through including a dummy variable if the respondent voted for a green party in the last general election. Two parties, which have a coverage of the whole country, are defined as green for this purpose. GroenLinks (GreenLeft) defines itself as 'green', 'social' and 'tolerant' and embraces environmentalism and a fair distribution of wealth and resources. It is part of the 'Greens-European Free Alliance' in the European Parliament. Partij van de Dieren (Party for the Animals) states animal welfare and animal rights as well as a broader environmentalism as its main goals. It is part of the 'European United Left-Nordic Green Left' in the European Parliament. Next to covering environmental topics, they can both be considered left-wing political parties. Even though voting for a green party does not identify environmental mindedness in all aspects, we assume that it can partly indicate if a person chooses to consider the environment in decision-making. All the above-mentioned independent variables are considered in all four analyses.

When analyzing carsharing users (Analysis 2 and 3) we additionally consider variables on motives. The literature review shows that motives to adopt carsharing range from cost reduction and convenience gains to environmental considerations. We therefore include three dummy variables stating if the most important reason to adopt carsharing was cost, convenience or the environment respectively.

In the analysis of the use frequency (Analysis 2) we additionally control for the type of carsharing by including dummy variables on only B2C carsharing use and only P2P carsharing use.

In the analysis of the willingness to become a provider on a P2P carsharing platform (Analysis 4.1 and 4.2), two more independent variables are considered. The attitude and experience towards lending one's private car to someone are taken into account by including a dummy variable if a respondent lends his/her own car to friends or family. Furthermore, we control for trust, which is considered to be of high importance when participating in the sharing economy. We proxy the perceived trust or safety in a municipality influencing the decision to lend a car to others by including a variable on the number of crimes per 1000 inhabitants in the postcode area of the respondent. Even though trust can be influenced by many other aspects, the crime rate can give an insight into how safe a neighborhood might be considered by its inhabitants, but implications of results need to be interpreted with care. Table 3 gives an overview of the independent variables that are considered in each analysis.

Each of the six analyses follows two steps. First, we analyze each independent variable and its influence on the respective dependent variable individually in a univariate regression analysis. These analyses are conducted in order to identify which of the independent variables have possibly large impact on explaining the dependent variable. In a second step, we set up a model including all independent variables that showed a significant influence in the univariate analysis. Due to the limited numbers of cases we decided to use this two-step process instead of including all independent variables in one multivariate analysis right away. 
Table 3

Independent variables.

\begin{tabular}{|c|c|c|c|c|c|}
\hline \multicolumn{2}{|c|}{ Considered independent variables } & \multicolumn{4}{|l|}{ Analysis } \\
\hline & & \multicolumn{3}{|l|}{ users } & \multirow{2}{*}{$\begin{array}{l}\text { providers } \\
4.1 \text { and } 4.2 \\
\text { Adoption as a } \\
\text { provider }\end{array}$} \\
\hline & & $\begin{array}{l}1.1 \text { and } 1.2 \\
\text { Adoption as a } \\
\text { user }\end{array}$ & $\begin{array}{l}2 \\
\text { Frequency of use }\end{array}$ & $\begin{array}{l}3 \\
\text { Carsharing type }\end{array}$ & \\
\hline \multirow[t]{6}{*}{ Socio-demographics } & Age & $\mathrm{x}$ & $\mathrm{x}$ & $\mathrm{x}$ & $\mathrm{x}$ \\
\hline & Gender & $\mathrm{x}$ & $\mathrm{x}$ & $\mathrm{x}$ & $\mathrm{x}$ \\
\hline & Household income level (27 levels) & $\mathrm{x}$ & $\mathrm{x}$ & $\mathrm{x}$ & $\mathrm{x}$ \\
\hline & Education level (8 levels) & $\mathrm{x}$ & $\mathrm{x}$ & $\mathrm{x}$ & $\mathrm{x}$ \\
\hline & Living in G4 city & $\mathrm{x}$ & $\mathrm{X}$ & $\mathrm{x}$ & $\mathrm{x}$ \\
\hline & Children in household & $\mathrm{x}$ & $\mathrm{x}$ & $\mathrm{x}$ & $\mathrm{x}$ \\
\hline \multirow[t]{2}{*}{ Access to transportation set } & No car in household & $\mathrm{x}$ & $\mathrm{x}$ & $\mathrm{x}$ & \\
\hline & Public transport subscription & $\mathrm{x}$ & $\mathrm{x}$ & $\mathrm{X}$ & $\mathrm{x}$ \\
\hline \multirow[t]{2}{*}{ Attitude } & Green party voter & $\mathrm{x}$ & $\mathrm{x}$ & $\mathrm{x}$ & $\mathrm{x}$ \\
\hline & $\begin{array}{l}\text { Lending attitude: Sharing own car with } \\
\text { friends or family }\end{array}$ & & & & $\mathrm{x}$ \\
\hline \multirow[t]{3}{*}{ Motivation } & Most important reason: Cost & & $\mathrm{x}$ & $\mathrm{x}$ & \\
\hline & Most important reason: Convenience & & $\mathrm{x}$ & $\mathrm{x}$ & \\
\hline & Most important reason: Environment & & $\mathrm{x}$ & $\mathrm{x}$ & \\
\hline Carsharing type & Only P2P or only $\mathrm{B} 2 \mathrm{C}$ user & & $\mathrm{x}$ & & \\
\hline Trust & Crime numbers & & & & $\mathrm{x}$ \\
\hline
\end{tabular}

1 The question for this variable was formulated in the survey as follows: "In the past 12 months, have you lent your own car to an acquaintance (family, friends, acquaintances)?" The question for the dependent variable on the provision of a car on a P2P platform was formulated as follows: "In the last 12 months, have you rented your own car to a private individual through an organization?".

\section{Results}

\subsection{Descriptive characterization of carsharing adopters}

The Dutch carsharing users of our sample are similar in their socio-demographics to earlier studies and, partly, to early adopters of innovations in general. Table 4 presents the descriptive statistics on adopter groups of carsharing as user and Table 5 on adopter groups of the provision of cars on P2P carsharing platforms. Note that most characteristics of potential adopters lie in between the characteristics of adopters and the group of not interested non-adopters.

We observe an equal amount of males and females adopting carsharing as users and a mean age of 46 years, ranging from 19 to 85 and spreading quite equally between the age groups of 25-70. The level of education of carsharing users is much higher than the Dutch average with $63 \%$ of carsharing users having at least a bachelor's degree, whereas the household income is not particularly high with the mode at an income category of $38,800 €-51,300 €$. As reported in the literature, carsharing users often live in densely populated areas. Indeed, many users in our sample live in the four largest cities of the Netherlands. About a fourth of the respondents lives in households with children. More than half of the carsharing users live in car-free households and two-thirds have a public transport subscription; amounts that are significantly higher than those of the non-adopters. Additionally, we observe a car purchase avoidance through the adoption of carsharing: 19\% of carsharing users 'would have' and 39\% 'would have maybe' purchased a car if they had not started using carsharing. Also, strong attitudes towards the environment can be observed in carsharing users: $18 \%$ of carsharing users have voted for a green party in the last general election against $4 \%$ of the total Dutch population. At the same time, the environment is not the main motivation for carsharing according to the majority of respondents. Only $9 \%$ of respondents mentioned it as the most important reason to adopt carsharing, while $40 \%$ stated that the most important reason to carshare is the cost savings and $11 \%$ stated the convenience of not owning a car. The reasons why potential adopters have not adopted carsharing so far are manifold: while many mention that they still have their own car or that it just has not happened yet (40\% and $24 \%$ of respondents respectively), others also state that they are missing information on the option or can easily get a car from family or 
Table 4

Descriptive statistics of carsharing users by adopter group.

\begin{tabular}{|c|c|c|c|c|}
\hline & \multirow{2}{*}{$\begin{array}{l}\text { Adopter of carsharing as a } \\
\text { user }(\mathrm{n}=238)\end{array}$} & \multirow{2}{*}{$\begin{array}{l}\text { Non-adopter } \\
(\mathrm{n}=1597)\end{array}$} & \multicolumn{2}{|l|}{ Non-adopter } \\
\hline & & & $\begin{array}{l}\text { Potential adopter } \\
(\mathrm{n}=200)\end{array}$ & $\begin{array}{l}\text { No interest } \\
(\mathrm{n}=1397)\end{array}$ \\
\hline Mean age & 45.6 & 50.4 & 45.2 & 51.1 \\
\hline Male & $51 \%$ & $46 \%$ & $39 \%$ & $46 \%$ \\
\hline $\begin{array}{l}\text { Mean education level }[8 \text { levels from } 1=\text { low (no school } \\
\text { degree) to } 8=\text { high (university master/PhD)] }\end{array}$ & 6.5 & 5.8 & 6.1 & 5.7 \\
\hline $\begin{array}{c}\text { Mean household income level }[27 \text { levels from } 1=\text { low (less } \\
\text { than } 4600 € \text { per year) to } 27=\text { high }(310,700 € \text { or more) }]\end{array}$ & 14.2 & 13.9 & 12.8 & 14.1 \\
\hline Children in household & $26 \%$ & $23 \%$ & $25 \%$ & $23 \%$ \\
\hline Green party vote & $19 \%$ & $6 \%$ & $10 \%$ & $6 \%$ \\
\hline Public transport subscription & $68 \%$ & $38 \%$ & $49 \%$ & $37 \%$ \\
\hline No car in household & $54 \%$ & $16 \%$ & $30 \%$ & $14 \%$ \\
\hline Living in G4 city & $43 \%$ & $25 \%$ & $31 \%$ & $24 \%$ \\
\hline
\end{tabular}

Table 5

Descriptive statistics of carsharing providers by adopter group.

\begin{tabular}{|c|c|c|c|c|}
\hline & \multirow{2}{*}{$\begin{array}{l}\text { Adopter of providing car on } \\
\text { P2P platform }(n=42)\end{array}$} & \multirow{2}{*}{$\begin{array}{l}\text { Non-adopter (but car } \\
\text { owner) }(\mathrm{n}=1447)\end{array}$} & \multicolumn{2}{|l|}{ Non-adopter } \\
\hline & & & $\begin{array}{l}\text { Potential adopter } \\
(\mathrm{n}=149)\end{array}$ & $\begin{array}{l}\text { No interest } \\
(\mathrm{n}=1298)\end{array}$ \\
\hline Mean age & 45.4 & 51.2 & 46.8 & 51.7 \\
\hline Male & $60 \%$ & $47 \%$ & $47 \%$ & $47 \%$ \\
\hline $\begin{array}{l}\text { Mean education level }[8 \text { levels from } 1=\text { low (no school } \\
\text { degree) to } 8=\text { high (university master/PhD) }]\end{array}$ & 6.6 & 5.8 & 6.0 & 5.7 \\
\hline $\begin{array}{l}\text { Mean household income level }[27 \text { levels from } 1=\text { low } \\
\text { (less than } 4600 € \text { per year) to } 27=\text { high }(310,700 € \\
\text { or more)] }\end{array}$ & 14.9 & 14.4 & 13.9 & 14.5 \\
\hline Children in household (Mean) & $40 \%$ & $26 \%$ & $25 \%$ & $26 \%$ \\
\hline Green party vote & $14 \%$ & $6 \%$ & $9 \%$ & $6 \%$ \\
\hline Public transport subscription & $50 \%$ & $36 \%$ & $43 \%$ & $35 \%$ \\
\hline Living in G4 city & $29 \%$ & $21 \%$ & $32 \%$ & $20 \%$ \\
\hline Sharing own car with friends or family & $60 \%$ & $35 \%$ & $59 \%$ & $32 \%$ \\
\hline Number of crimes per 1000 inhabitants & 75.6 & 70.5 & 84.1 & 68.9 \\
\hline
\end{tabular}

friends. Potential adopters state that they would start carsharing when car ownership becomes too expensive (46\%) or when they would need to buy a new car (25\%).

Respondents that provide their own car to others through a P2P carsharing platform are more often male (60\%) and have a mean age of 45. The level of education is again high compared to the national average, with two-thirds of adopters having at least a bachelor's degree. The income of car providers is slightly higher compared to non-adopters as well as carsharing users, and the mode lies in the 51,300-65,000€ annual household income category. Compared to non-adopters as well as carsharing users, a large number of P2P providers live with children in the household and $14 \%$ of car providers have voted for a green party in the last political election. Many adopters and respondents that are considering to make their car available to others through a P2P carsharing platform also provide their car privately to friends and family, while respondents not interested in sharing their car on a P2P platform do this much less. The main points of concern of people not providing their car on a P2P platform are the risk of damage (28\%), that they need more information first $(27 \%)$ or that they need their car too often themselves $(27 \%)$. 
Table 6

Analysis 1.1 Adopters vs non-adopters of carsharing as user with 9 univariate analyses and 1 multivariate logistic regression analysis.

\begin{tabular}{|c|c|c|c|}
\hline \multirow{3}{*}{$\begin{array}{l}\text { Reference category: Non-adopter of carsharing as a } \\
\text { user }\end{array}$} & \multicolumn{2}{|c|}{ Univariate log. regressions (log. regression of each IV) } & \multirow{3}{*}{$\begin{array}{l}\text { Multivariate log. regression with significant } \\
\text { variables } \\
\text { Adopter of carsharing as user }\end{array}$} \\
\hline & & Adopter of carsharing as user & \\
\hline & Nagelkerke $\mathrm{R}^{2}$ & $\operatorname{Exp}(B)$ & \\
\hline Age & 0.020 & $0.980^{\text {iktex }}$ & 0.993 \\
\hline Gender $($ Female $=0$, Male $=1)$ & 0.002 & 1.238 & \\
\hline Education level (low to high) & 0.046 & $1.366^{\text {tithen }}$ & $1.242^{\text {ikk*k }}$ \\
\hline Household income (low to high) & 0.001 & 1.020 & \\
\hline Dummy Children $(<18)$ in household $(=1)$ & 0.001 & 1.211 & \\
\hline Dummy Green party voter $(=1)$ & 0.033 & $3.342^{\text {inkix }}$ & $1.870^{\text {*kikek }}$ \\
\hline Dummy Public transport subscription $(=1)$ & 0.075 & $3.467^{\text {mikn }}$ & $2.275^{* k * k}$ \\
\hline Dummy Carfree household $(=1)$ & 0.149 & $6.330^{\text {situm }}$ & $4.490^{* * * * *}$ \\
\hline \multirow[t]{3}{*}{ Dummy G4 cities $(=1)$} & 0.032 & $2.267^{m+k * x}$ & 1.108 \\
\hline & & & $N=1636$ \\
\hline & & & Nagelkerke $\mathrm{R}^{2}=0.228$ \\
\hline
\end{tabular}

"Significance at the 0.1 level.

*** Significance at the 0.05 level.

$* * *$ Significance at the 0.01 level

For both the income and the green voting variables, as well as for the dependent use frequency variable, we find some missing values in the data, which reduces the sample size of the regression analyses. We report these in the following section.

\subsection{Logistic regressions}

The first analysis (1.1) explores which variables influence the chance to be a user of carsharing compared to the group of nonadopters (Table 6). The group of non-adopters acts as the reference category of the dependent variable. In the univariate regressions, which include each independent variable separately, we observe significant influences of age, education, green voting, public transport subscription, car-free household and living in a G4 city on the likelihood of belonging to the adopter group compared to the non-adopter group. The multivariate regression analysis includes the independent variables that were shown to be significant in the univariate analysis. The Nagelkerke indicator (a Pseudo $\mathrm{R}^{2}$ ) of the multivariate regression equals 0.228 , which means that $22.8 \%$ of the variance is explained through these included variables. Apart from age and living in the G4 cities, all variables (i.e. education, green voting, public transport subscription, and car-free household) are significant when comparing carsharing users to non-adopters. The education level increasing by one level increases the likelihood to be a carsharer by $24 \%$. Similar to other studies (Shaheen, 1999 ; Efthymiou et al., 2013; Becker et al., 2017), we find a positive influence of environmental mindedness and the use of public transportation on carsharing adoption. Voting for a green party almost doubles the chance of being a carsharing user rather than being not interested. Having a public transport subscription increases the likelihood of being a carsharer by a factor of 2.3. The largest effect is observed for the variable of car-free households - having no car in the household increases the likelihood of being a carsharing user by a factor of 4.5 .

Analysis 1.2 compares the group of potential adopters to non-adopters that are not interested in adopting carsharing as a user (Table 7). In the univariate regressions all variables, besides the variable on children in the household, show significant influences when analyzed separately. In the following multivariate regression, the variables age, income and having a public transport subscription have a significant effect. For an increase of one year in age the likelihood to be a potential adopter decreases by $2 \%$. This is consistent with the trend of the younger generation being more open to gaining access to assets rather than owning them (Rifkin, 2015). Interestingly, a lower income raises the likelihood of a respondent to be a potential adopter, which can be interpreted to be in line with arguments that carsharing can be a way to gain automobility access for lower income groups that do not have the means to buy or own a car. Lower income respondents might see opportunities for cost-saving in carsharing, although living in a car-free household does not have a significant influence on carsharing adoption. A positive influence to be a potential adopter is observed for respondents who hold a public transport subscription.

Carsharing is not the main means of transport for most carsharing users but rather another option in a wider set of transportation modes in use. Some carsharing organizations ask no monthly or annual subscription fees and do not all require a registration fee, which makes it easy for people to sign up for the service and rarely use it. Therefore, it is valuable to analyze which groups of people 
Table 7

Analysis 1.2 Potential adopters of carsharing as user vs. no interest group with 9 univariate analyses and 1 multivariate logistic regression analysis.

\begin{tabular}{|c|c|c|c|}
\hline \multirow{3}{*}{$\begin{array}{l}\text { Reference category: Not interested in adopting } \\
\text { carsharing as a user }\end{array}$} & \multicolumn{2}{|c|}{$\begin{array}{l}\text { Univariate log. regressions (log. regression of each } \\
\text { IV) }\end{array}$} & \multirow{3}{*}{$\begin{array}{l}\text { Multivariate log. regression with significant } \\
\text { variables } \\
\text { Potential adopter of carsharing as user }\end{array}$} \\
\hline & & $\begin{array}{l}\text { Potential adopter of carsharing as } \\
\text { user }\end{array}$ & \\
\hline & Nagelkerke $\mathrm{R}^{2}$ & $\operatorname{Exp}(B)$ & \\
\hline Age & 0.029 & $0.976^{\text {wexke }}$ & $0.977^{m+1 / k \cdot k}$ \\
\hline Gender $($ Female $=0$, Male $=1)$ & 0.004 & $0.755^{*}$ & 1.236 \\
\hline Education level (low to high) & 0.008 & $1.132^{* * * *}$ & 1.104 \\
\hline Household income (low to high) & 0.020 & $0.928^{* 2 \times 2 k x}$ & 0.956 \\
\hline Dummy Children $(<18)$ in household $(=1)$ & 0.000 & 1.106 & \\
\hline Dummy Green party voter $(=1)$ & 0.005 & $1.792^{* *}$ & 1.360 \\
\hline Dummy Public transport subscription $(=1)$ & 0.013 & $1.646^{\text {vincole }}$ & $1.495^{* * *}$ \\
\hline Dummy Carfree household $(=1)$ & 0.034 & $2.674^{* * 2 k t}$ & 1.488 \\
\hline \multirow[t]{2}{*}{ Dummy G4 cities $(=1)$} & 0.005 & $1.424^{* *}$ & 1.081 \\
\hline & & & $N=1112$ \\
\hline
\end{tabular}

* Significance at the 0.1 level.

** Significance at the 0.05 level.

$* * *$ Significance at the 0.01 level.

use carsharing as a regular part of their transportation mix and who uses carsharing only as an infrequent additional mode of transport for special circumstances. The second analysis thus explores which variables influence the frequency of use (Table 8). Infrequent users are characterized as adopters using carsharing five times per year or less, while frequent users are respondents using carsharing more than five times per year. The studies by Becker et al. (2017) and Habib et al. (2012) showed that frequency of use is higher for younger to middle-aged male adopters who have high income and live in a car-free household. Partly in line with this, our first analysis of all independent variables in separate univariate logistic regressions finds education, a public transport subscription, living in a car-free household and the two variables on the type of carsharing (only B2C or only P2P use) to be significantly influencing the likelihood to be a frequent carsharing user. In the following multivariate regression analysis, we find that the education level is significant, with a higher level of education increasing the likelihood to be a frequent user, as well as a positive influence of holding a public transport subscription. The latter increases the likelihood by a factor of 2.29 . When respondents only use P2P carsharing, the likelihood to be a frequent user of carsharing is smaller. Frequent users thus tend to prefer the more convenient and professional B2C service or use both services.

The use frequency seems to differ between users of P2P and B2C carsharing and, since the value proposition of B2C and P2P carsharing business models differs, more factors can be considered to have an influence on choosing a type of carsharing. The third analysis therefore explores which variables explain the preference to be a B2C user over a P2P user (Table 9). The univariate regressions show that education and income, as well as having a public transport subscription and living without a car and in a G4 city, have significant effects when analyzed separately. Cost as a main motive to join carsharing positively influences the likelihood to be a B2C user, while the environment as a main motive negatively influences the likelihood to be a B2C user compared to a P2P user. In the following multivariate regression analyses we include the above-mentioned significant socio-demographic variables. We find that higher education and income levels positively influence the likelihood of a respondent to be a B2C user compared to a P2P user. Increasing the education level by 1 increases the chance of being part of the B2C user group by $25 \%$, while increasing the income level raises it by $13 \%$. Since B2C carsharing is generally more expensive than P2P carsharing, a higher income might be needed in order to use the service, while people with lower income may rather opt for the more affordable option of P2P carsharing. Having a public transport subscription and no car in the household positively influences being a B2C user over a P2P user. B2C users might thus be using a more multi-modal, public transport-oriented mobility composition without relying on a privately-owned car. We leave out the variables on motives to join, because of rather low n numbers that would not support the inclusion of too many independent variables. For robustness checks we did include cost and environment as reasons in a regression with seven independent variables and we also checked the three reason variables together in another regression but did not find significant influences. Low $n$ numbers force us to interpret the results with care, but our robustness checks make us believe that results are stable.

For all other variables, no significant influence is identified, which means that the same type of people is attracted to the different services. The adopters of the two different carsharing types are thus rather similar and the choice of one form over the other is 
Table 8

Analysis 2 Frequency of carsharing use with 14 univariate analyses and 1 multivariate logistic regression analysis.

\begin{tabular}{|c|c|c|c|}
\hline \multirow[b]{2}{*}{ Reference category: Low-frequency use } & \multicolumn{2}{|c|}{ Univariate log. regressions (log. regression of each IV) } & \multirow{2}{*}{$\begin{array}{l}\text { Multivariate log. regression with significant } \\
\text { variables } \\
\text { High-frequency use } \\
\text { Exp(B) }\end{array}$} \\
\hline & Nagelkerke $\mathrm{R}^{2}$ & $\begin{array}{l}\text { High-frequency use } \\
\operatorname{Exp}(B)\end{array}$ & \\
\hline Age & 0.003 & 1.007 & \\
\hline Gender $($ Female $=0$, Male $=1)$ & 0.003 & 0.813 & \\
\hline Education level (low to high) & 0.024 & $1.216^{*}$ & $1.221^{*}$ \\
\hline Household income (low to high) & 0.008 & 1.039 & \\
\hline Dummy Children $(<18)$ in household $(=1)$ & 0.003 & 1.257 & \\
\hline Dummy Green party voter $(=1)$ & 0.000 & 1.017 & \\
\hline Dummy Public transport subscription $(=1)$ & 0.076 & $2.955^{k * k x}$ & $2.291^{* *}$ \\
\hline Dummy Carfree household $(=1)$ & 0.021 & $1.687^{*}$ & 1.224 \\
\hline Dummy G4 cities $(=1)$ & 0.006 & 0.766 & \\
\hline Most important reason to carshare: Costs $(=1)$ & 0.003 & 0.818 & \\
\hline $\begin{array}{l}\text { Most important reason to carshare: Convenience } \\
\qquad(=1)\end{array}$ & 0.015 & 1.973 & \\
\hline $\begin{array}{l}\text { Most important reason to carshare: Environment } \\
\qquad(=1)\end{array}$ & 0.021 & 2.948 & \\
\hline Dummy only B2C user $(=1)$ & 0.037 & $2.039^{* *}$ & 1.157 \\
\hline \multirow[t]{2}{*}{ Dummy only P2P user $(=1)$} & 0.122 & $0.119^{* * * k}$ & $0.168^{\text {knklk }}$ \\
\hline & & & $N=197$ \\
\hline
\end{tabular}

* Significance at the 0.1 level.

** Significance at the 0.05 level.

$* * *$ Significance at the 0.01 level.

explained by a higher income and level of education that makes it easier to pay for the more expensive form of carsharing (B2C) and a transportation use set that is not focused on a private car.

Since the diffusion of P2P carsharing also requires people that are willing to share their private car through a carsharing platform, it is of interest to identify who becomes the adopter of carsharing as a car provider. Analysis 4.1 and 4.2 explore factors influencing a respondent to be an adopter compared to a non-adopter (Table 10), or a respondent to be a potential adopter compared to not being interested in providing a car on a P2P platform respectively (Table 11). When comparing adopters to non-adopters, the univariate regressions show that age, education and family composition, green voting, public transport subscription and, with the largest effect, car provision to friends and family have an effect on adoption when analyzed in separate regression analyses. ${ }^{3}$ We find a significant influence of age for the adopter group compared to non-adopters: the age increasing by one year makes it $2 \%$ less likely to be an adopter. A higher education level has a positive effect on being an adopter compared to a non-adopter. Both results are in line with findings of Dill et al. (2017) and Shaheen et al. (2018), who also identify P2P car providers to be younger and have a higher education level compared to the population average. The likelihood to be an adopter increases when holding a public transport subscription, which can be interpreted as people who are not completely dependent on their private car but also use other mobility options to be more likely to rent out their car on a P2P platform. The largest effect on being a car provider on a P2P platform comes from already providing a private car in an 'unorganized' way to friends and family. When sharing a car informally, the likelihood to be an adopter of 'organized' car provision through a P2P platform increases by a factor of 2.4 . It thus seems to be of high importance that people are

\footnotetext{
${ }^{3}$ When combining these independent variables in a regression we have to take into account the rather low number of observations $s$ for the adopter group. To check for the robustness of our results we have additionally calculated a model without the green voting variable, which increases the number of cases, and get the same results on which variables deliver significant influences. Therefore, we feel confident that the adopter categories are distinct enough and the model as presented here robustly identifies the influential variables on the likelihood of being a P2P car provider adopter. Nonetheless, results of a regression with a low number of observations in a category always need to be interpreted with care.
} 
Table 9

Analysis 3 B2C vs P2P Carsharing type with 12 univariate analyses and 1 multivariate logistic regression analysis.

\begin{tabular}{|c|c|c|c|}
\hline \multirow[b]{2}{*}{ Reference category: P2P user } & \multicolumn{2}{|c|}{ Univariate log. regressions (log. regression of each IV) } & \multirow{2}{*}{$\begin{array}{l}\text { Multivariate log. regression with significant } \\
\text { variables } \\
\text { B2C user } \\
\text { Exp(B) }\end{array}$} \\
\hline & Nagelkerke $\mathrm{R}^{2}$ & $\begin{array}{l}\text { B2C user } \\
\operatorname{Exp}(B)\end{array}$ & \\
\hline Age & 0.007 & 0.987 & \\
\hline Gender $($ Female $=0$, Male $=1)$ & 0.000 & 1.015 & \\
\hline Education level (low to high) & 0.037 & $1.277^{* * *}$ & $1.247^{*}$ \\
\hline Household income (low to high) & 0.061 & $1.114^{k * k x}$ & $1.128^{* x+k}$ \\
\hline Dummy Children $(<18)$ in household $(=1)$ & 0.002 & 0.804 & \\
\hline Dummy Green party voter $(=1)$ & 0.003 & 1.306 & \\
\hline Dummy Public transport subscription $(=1)$ & 0.072 & $2.937^{\text {knkn }}$ & $1.998^{*}$ \\
\hline Dummy Carfree household $(=1)$ & 0.055 & $2.522^{* k *}$ & $2.265^{* * x}$ \\
\hline Dummy G4 cities $(=1)$ & 0.025 & $1.886^{*}$ & 1.507 \\
\hline Most important reason to carshare: Costs $(=1)$ & 0.025 & $1.929^{*}$ & \\
\hline $\begin{array}{l}\text { Most important reason to carshare: Convenience } \\
\qquad(=1)\end{array}$ & 0.002 & 1.286 & \\
\hline $\begin{array}{l}\text { Most important reason to carshare: Environment } \\
\qquad(=1)\end{array}$ & 0.027 & $0.382^{x / k}$ & \\
\hline
\end{tabular}

$N=183$

Nagelkerke $\mathrm{R}^{2}=0.178$

* Significance at the 0.1 level.

** Significance at the 0.05 level.

$* * *$ Significance at the 0.01 level.

open to the idea of somebody else driving their private car, which supports the claims that higher levels of trust in others and a low attachment to their car are critical to the adoption of P2P carsharing in the role of car providers. This is in line with the descriptive findings (Section 4.1) on the main concerns of car owners not to provide their car to others due to the risk of damage or because they need their car too often themselves. A lower car-dependence, indicated by the positive influence of a public transport subscription, is furthermore essential for car owners to adopt carsharing as car providers.

When comparing the potential P2P car providers to the group of non-adopters that are not interested to do so (Table 11), we find in the univariate regression analyses that age, education, income, public transport subscription, living in a G4 city, crime rate and the informal sharing of a car show a significant effect. In the following multivariate regression analysis only age and informal sharing are identified to have a significant effect. Younger people seem slightly more open to adopting carsharing as a car provider and we again observe the large positive effect of informal sharing also for potentially adopting P2P carsharing as a car provider.

\section{Discussion}

Based on the results of this study, four main findings can be highlighted: (1) adopters of carsharing constitute a distinct group of people whose characteristics are partly consistent with those described in innovation-adoption theory and in previous carsharing research, and they show a lower car dependence; (2) B2C and P2P users differ in terms of education and income, as well as in terms of their use of a multi-modal transport set; (3) experience with sharing a car informally and lower car-dependency increases the likelihood to become a car provider on P2P platforms; (4) carsharing in the Netherlands is not only a big city phenomenon. We elaborate on these findings below.

\subsection{Findings}

First, the unique dataset analyzed in this study, including next to carsharing adopters also groups of potential adopters and not interested non-adopters, makes it possible to draw the conclusion that adopters are a clearly distinct group of people. The variables that significantly influence the likelihood for a person to be an adopter are partly in line with Rogers' (2003) early adopter description, as well as with findings from previous studies. Carsharing is especially popular among people with higher levels of 
Table 10

Analysis 4.1 Adopter of carsharing as provider vs non-adopter with 10 univariate analyses and 1 multivariate logistic regression analysis.

\begin{tabular}{|c|c|c|c|}
\hline \multirow{3}{*}{$\begin{array}{l}\text { Reference category: Non-adopter of carsharing as a provider } \\
\text { (but car owner) }\end{array}$} & \multicolumn{2}{|c|}{$\begin{array}{l}\text { Univariate log. regressions (log. regression of each } \\
\text { IV) }\end{array}$} & \multirow{3}{*}{$\begin{array}{l}\text { Multivariate log. regression with } \\
\text { significant variables } \\
\text { Adopter of carsharing as provider } \\
\text { Exp(B) }\end{array}$} \\
\hline & & $\begin{array}{l}\text { Adopter of carsharing as } \\
\text { provider }\end{array}$ & \\
\hline & Nagelkerke $\mathrm{R}^{2}$ & $\operatorname{Exp}(B)$ & \\
\hline Age & 0.017 & $0.976^{* * *}$ & 0.979 \\
\hline Gender $($ Female $=0$, Male $=1)$ & 0.008 & 1.677 & \\
\hline Education level (low to high) & 0.033 & $1.431^{* * n * k}$ & $1.342^{* * *}$ \\
\hline Household income (low to high) & 0.003 & 1.044 & \\
\hline Dummy Children $(<18)$ in household $(=1)$ & 0.013 & $1.972^{* *}$ & 1.475 \\
\hline Dummy Green party voter $(=1)$ & 0.011 & $2.673^{* * *}$ & 2.040 \\
\hline Dummy Public transport subscription $(=1)$ & 0.010 & $1.794^{*}$ & $1.810^{*}$ \\
\hline Dummy G4 cities ( = 1) & 0.004 & 1.517 & \\
\hline Crime rate in municipality & 0.001 & 1.001 & \\
\hline \multirow[t]{3}{*}{ Dummy provision to friends and family $(=1)$} & 0.031 & $2.758^{\text {witen }}$ & $2.445^{* * *}$ \\
\hline & & & $N=1307$ \\
\hline & & & Nagelkerke $\mathrm{R}^{2}=0.089$ \\
\hline
\end{tabular}

* Significance at the 0.1 level.

** Significance at the 0.05 level.

$* * *$ Significance at the 0.01 level.

educational attainment and with persons living in car-free households. Our finding that gender and income do not have a significant influence on carsharing adoption is in line with the varying results on these variables in earlier studies. Our findings that carsharing adopters are more likely to have a positive attitude towards the environment and public transport are also in line with some of the earlier studies and, together with the higher likelihood of living in a car-free household, show that carsharing adopters can be characterized as being less car dependent.

What is more, innovation-adoption theories need to be extended with the new role category of 'provider-adopter' on two-sided platforms in e.g. the sharing economy. Findings of this research suggest that the roles of user and provider are different, and motives, barriers and attributes need to be identified to foster a balanced level of demand and supply. Two more points can be made on characterizing carsharing adopters: on one side, carsharing is often framed as a sustainable innovation, reducing car ownership and driven kilometers. Although we do not find the environment to be the main reason to adopt carsharing, an environmental attitude indicated by green voting positively influences the likelihood of adopting carsharing as a user. On the other side, a lower income influences people to be interested in adopting carsharing. Carsharing can thus act like a car access option for these cost-sensitive households that are not able to afford car ownership. These impacts of carsharing have not yet been clearly indicated by any of the previous studies. For these groups, who previously did not have access to a car, adopting carsharing may have a negative environmental impact as car kilometers are increased and the use of other (more environmentally friendly) modes might decrease. For other groups, carsharing can prevent car purchase or lead to selling a (second) car and an increased use of public transit resulting in an reduction in car-driven kilometers. Overall, it has been shown that the effect on reduced emissions is positive (Giesel and Nobis, 2016; Martin and Shaheen, 2011; Schreier et al., 2018).

Second, B2C and P2P users do not differ greatly except in terms of their education and income level, as well as their used transportation set. A higher level of educational attainment and income make users choose the more expensive but also more convenient form of B2C carsharing, while cost-sensitive users choose the less expensive P2P carsharing form. Users that have no private car in their household but are more public transport-oriented choose for B2C carsharing, which they also use more frequently than users only using P2P carsharing. With this, we confirm the findings of previous studies on B2C users (highlighted in Table 1, Section 2.3) that found the positive influence of having no or low car ownership, a public transport pass or a positive attitude towards public transport use to be influential on carsharing adoption. Our finding also suggests that, at the moment, P2P carsharing may be used primarily for special purposes or in special situations, whereas B2C users make it part of their normal routine. B2C users use carsharing in recurring occasions for which they need a car but find carsharing a sufficient option, and rely on public transit and active modes (e.g. walking, cycling) for all other cases. For the more specific circumstances in which users use P2P carsharing, like for example a weekend trip or moving, it could additionally be the case that private lending of cars between friends, family and 
Table 11

Analysis 4.2 Potential adopter of carsharing as provider versus no interest group with 10 univariate analyses and 1 multivariate logistic regression analysis.

\begin{tabular}{|c|c|c|c|}
\hline \multirow[b]{2}{*}{$\begin{array}{l}\text { Reference category: Not interested in adopting carsharing as a } \\
\text { provider (but car owner }\end{array}$} & \multicolumn{2}{|c|}{$\begin{array}{l}\text { Univariate log. regressions (log. regression of each } \\
\text { IV) }\end{array}$} & \multirow{2}{*}{$\begin{array}{l}\text { Multivariate log. regression with } \\
\text { significant variables } \\
\text { Potential adopter of carsharing as } \\
\text { provider } \\
\text { Exp(B) }\end{array}$} \\
\hline & Nagelkerke $\mathrm{R}^{2}$ & $\begin{array}{l}\text { Potential adopter of carsharing } \\
\text { as provider } \\
\operatorname{Exp}(\mathrm{B})\end{array}$ & \\
\hline Age & 0.019 & $0.979^{\text {knkex }}$ & $0.979^{* * * \times k}$ \\
\hline Gender $($ Female $=0$, Male $=1$ ) & 0.000 & 0.953 & \\
\hline Education level (low to high) & 0.007 & $1.127^{* k *}$ & 1.122 \\
\hline Household income (low to high) & 0.006 & $0.955^{*}$ & 0.966 \\
\hline Dummy Children $(<18)$ in household $(=1)$ & 0.000 & 0.953 & \\
\hline Dummy Green party voter $(=1)$ & 0.003 & 1.640 & \\
\hline Dummy Public transport subscription $(=1)$ & 0.005 & $1.401^{*}$ & 1.129 \\
\hline Dummy G4 cities $(=1)$ & 0.015 & $1.885^{\text {*k***}}$ & 1.512 \\
\hline Crime rate in municipality (low to high) & 0.006 & $1.002^{k * k}$ & 0.999 \\
\hline \multirow[t]{3}{*}{ Dummy provision to friends and family $(=1)$} & 0.054 & $3.013^{k+x k x}$ & $2.818^{* \ldots \neq k}$ \\
\hline & & & $N=1118$ \\
\hline & & & Nagelkerke $R^{2}=0.080$ \\
\hline
\end{tabular}

* Significance at the 0.1 level.

** Significance at the 0.05 level.

$* * *$ Significance at the 0.01 level.

neighbors takes place without a P2P organization acting as matchmaker. Since most B2C providers in the Netherlands charge some kind of fixed fees while P2P platforms do not, B2C users make a more financially committed choice and may only become a member of the service when they know they need it. The differences in adopter characteristics thus seem limited, whereas the usage patterns differ substantially between $\mathrm{B} 2 \mathrm{C}$ and P2P carsharing. These findings are important in the light of the ongoing convergence of the two business models foreshadowed by some B2C carsharing providers starting to offer both services (e.g., MyWheels) or P2P platforms getting into alliances with traditional rental companies (e.g., SnappCar with Europcar). P2P carsharing is becoming more convenient and professionalized ${ }^{4}$ through smart locks that make the key handover redundant, while at the same time B2C carsharing is becoming cheaper and better connected nationally and internationally. This suggests that, progressively, the convenience levels and price differences between the two forms of carsharing are likely to become smaller. Next to the convergence of B2C and P2P models it can also be pointed out that different forms of carsharing thrive in different environments (Münzel et al., 2018). While P2P carsharing can grow and scale-up also in more rural areas, B2C carsharing providers struggle with making cars profitable outside of cities because of low usage density.

Third, we provide first insights into the factors influencing people to rent out their car on a P2P platform, which is essential for a well-balanced system of supply and demand and, thus, the success of P2P carsharing platforms. The incentive to be able to make money by renting out a car on a P2P carsharing platform does not seem to convince many people to start providing their car on a platform. Instead, we find people who already provided a car informally to friends and family, are much more likely to provide via a P2P platform or are interested in doing so in the future. This suggests that P2P carsharing is a natural extension of an existing informal sharing practice already embraced by larger groups in society. Experience with trusting others to take good care of the car and a lower attachment and dependence on a car are essential for people to outweigh potential fears of damage. The current trend of people putting less emphasis on owning things and the rise of trust that is created through ratings and review systems on platforms can thus help increase the number of providers on P2P carsharing platforms.

Fourth, carsharing is often described as a city phenomenon that needs a high population density to function effectively. As found in earlier studies discussed in our literature review, a high density is identified as being influential for carsharing supply or use. Our data, however, do not support this framing of carsharing being only a big city phenomenon. We do not find a significant influence of living in one of the four largest cities in the Netherlands on carsharing adoption either as a user or as a provider.

\footnotetext{
${ }^{4}$ This development can be compared to the development of the accommodation platform Airbnb, which has professionalized tremendously, making it a more convenient experience for users and attracting professional providers (Benner, 2017).
} 


\subsection{Policy implications}

For multiple reasons, there is a lot of room for carsharing to grow, but the focus of policymakers, organizations and research should not lay solely on technology and business models. In addition, policymakers can take into account people's behavior patterns and the relation to the private car, and consider the possibilities of a multi-modal connected transportation system including carsharing. Multiple policy recommendations follow from this. First, given the overlap of B2C and P2P carsharing and the convergence of business models, policies do not need to focus so much on a specific treatment of different providers but rather lay out favorable conditions for a connected multi-modal transportation system that makes it easy for people to use public transport, shared cars and other modes to fulfil their mobility needs. Second, different providers could be required to share data and give access to their system to make the aggregation of different services possible. Third, sharing vehicles can be incentivized by generic campaigns covering all shared mobility modes, as well as giving preferential driving lane and parking access to shared cars. Next to these three points, it is of great importance that policy makers monitor the environmental effects of the different carsharing forms and in different environments. Carsharing only has a positive effect on the sustainability of the mobility system when it leads to a decrease in car dependence and adopters make use of a convenient multi-modal mobility system.

\subsection{Future research}

We argue that research into the current adoption patterns and possible future developments is highly valuable. The current adopters of carsharing seem to follow the typical early-adopter characteristics of being younger and having a higher status, which has a trendsetting power that can be utilized. Yet, our study also shows that cost and convenience are the main motivational factors for people to adopt carsharing, which suggests that carsharing can reach out to the mass market, and 'cross the chasm' as described by Moore (1991) to the early and late majority adopter groups of Rogers' (2003) diffusion of innovation model. These groups are made up by people who lack a strong environmental attitude, but rather look for a cost-efficient mobility option that supplements their transportation set. We find these first indicators and important factors, but future research needs to analyze which measures can really be successful in convincing people to share cars (as users and providers). It needs to be studied in more depth how carsharing can be made attractive to groups that could profit most of carsharing, but are not using it as much yet: lower income groups and people in rural areas where mobility options are more limited than in the city centers. Most previous research had small sample numbers or was focused on one city or carsharing provider, so research with larger datasets that include also other shared mobility modes and the connection to public transport would be of high value to strengthen our insights and check them for robustness. Since transportation systems are quite country specific, also more research in different countries is needed.

\subsection{Limitations}

This point brings us to the limitations of our study. Our insights are drawn from carsharing adopters in the Netherlands. Since the country is much denser populated and its transportation system is already less car-focused and offers better public transport including bike infrastructure compared to, for example, North America, results might not be perfectly generalizable. Although we find similar adopter characteristics, usage and reasons to adopt might play out differently in other settings. Since carsharing is still an earlyadopter phenomenon our dataset has a limited number of actual carsharing adopters, especially a low number of car providers active on P2P platforms. Lower numbers of observations reduce the number of influence factors that can be controlled for and can decrease the statistical power to detect effects. Nonetheless, robustness checks have shown that the influences identified are quite robust. Furthermore, some influence factors could only be proxied through indicators that give room to flaws and missed specificities. One example for this is assuming that green voting can be translated directly into strong environment mindedness or that everybody who is environmentally minded automatically votes for green parties. Here further research into attitudes and consumption behavior could deepen the understanding of motives for carsharing adoption.

\section{Acknowledgments}

Funding has been provided by the Dutch research council NWO, Dialogic, and the Rathenau Institute under the "Sustainable Business Models" program (no. 438-14-904). We thank TNS-NIPO for providing us with the survey data. We thank the three anonymous reviewers of this paper for their constructive critique which improved this article considerably. We thank Dr. Maryse Chappin for her help on improving the statistical analysis of our dataset. 


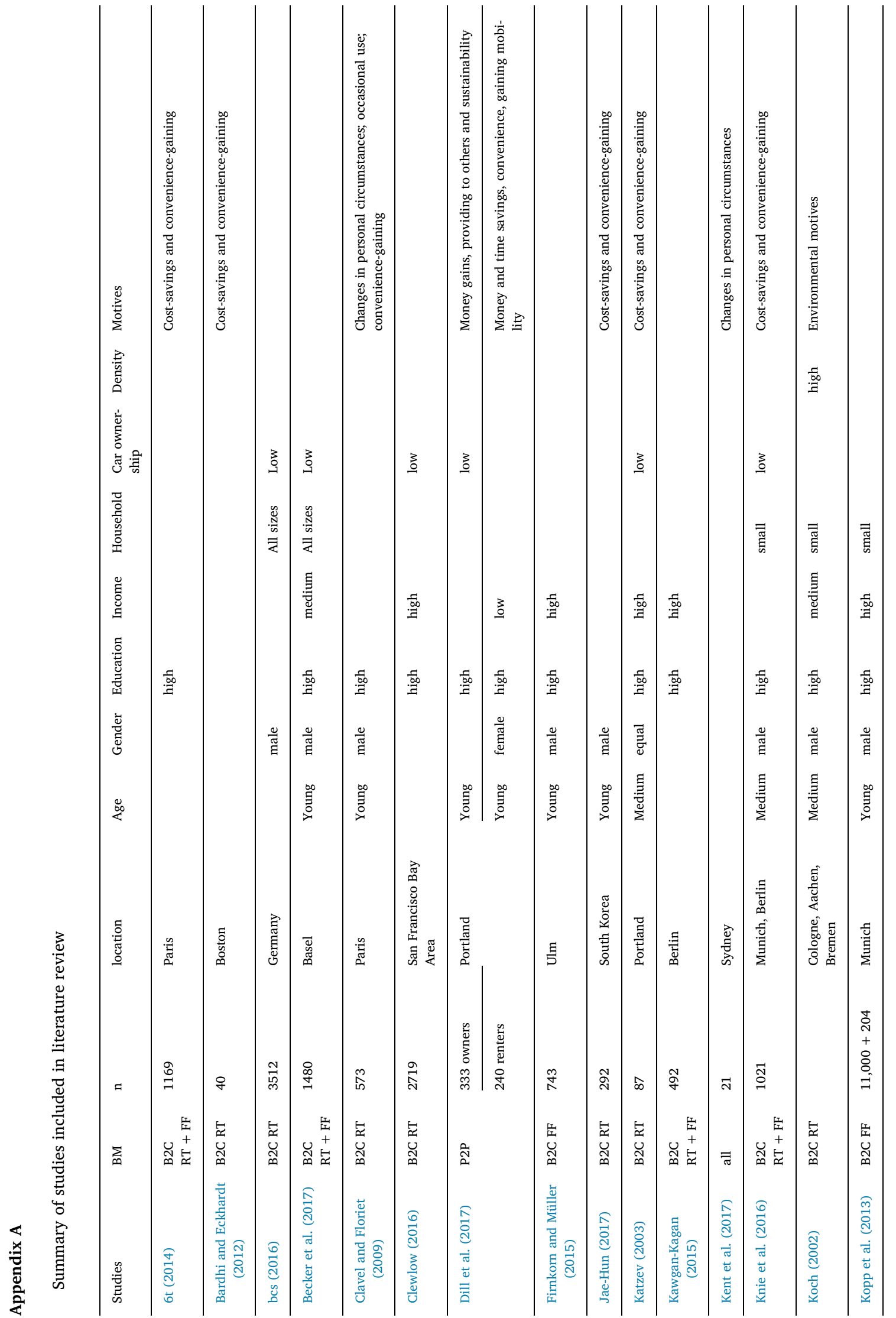




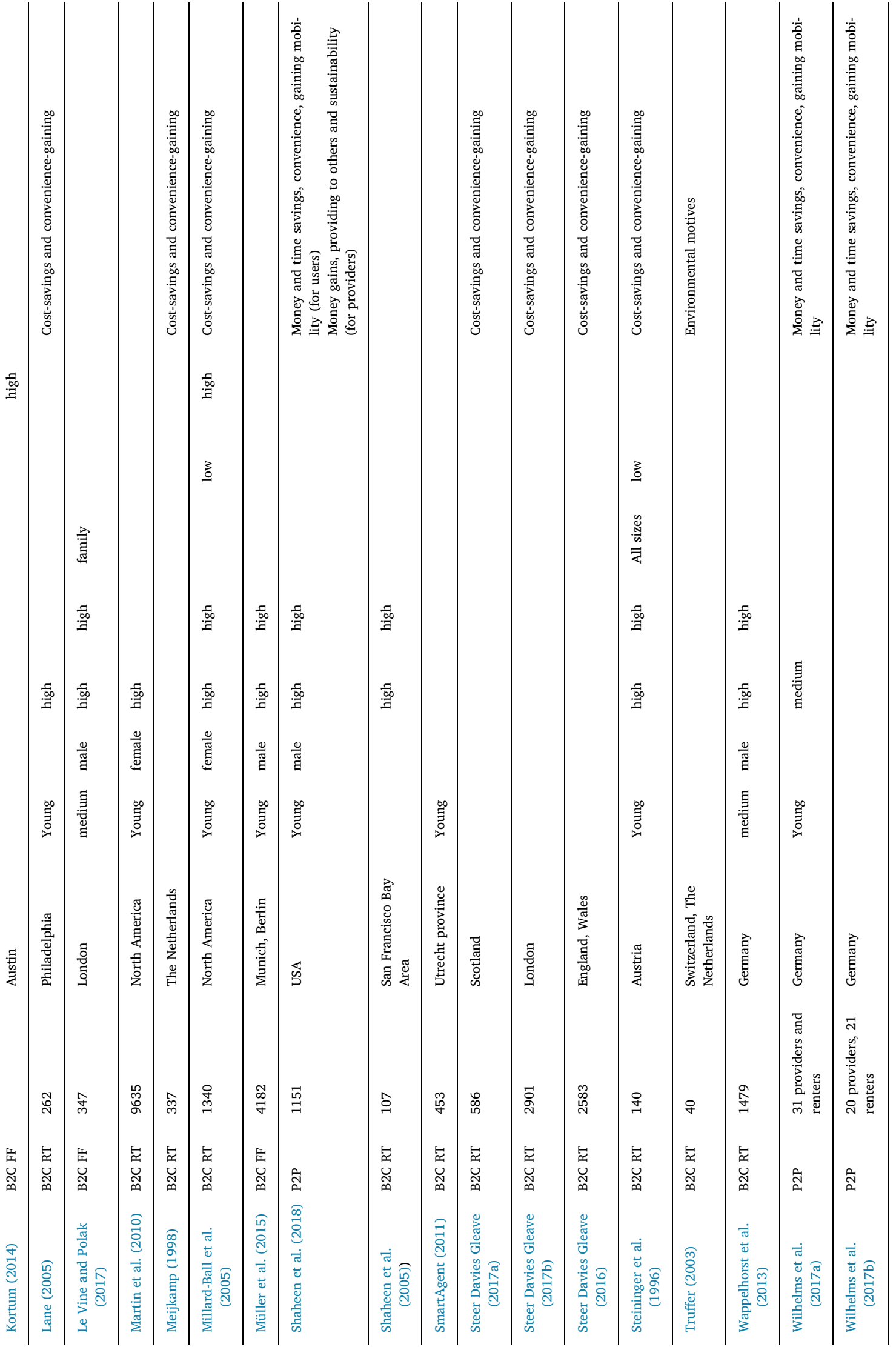




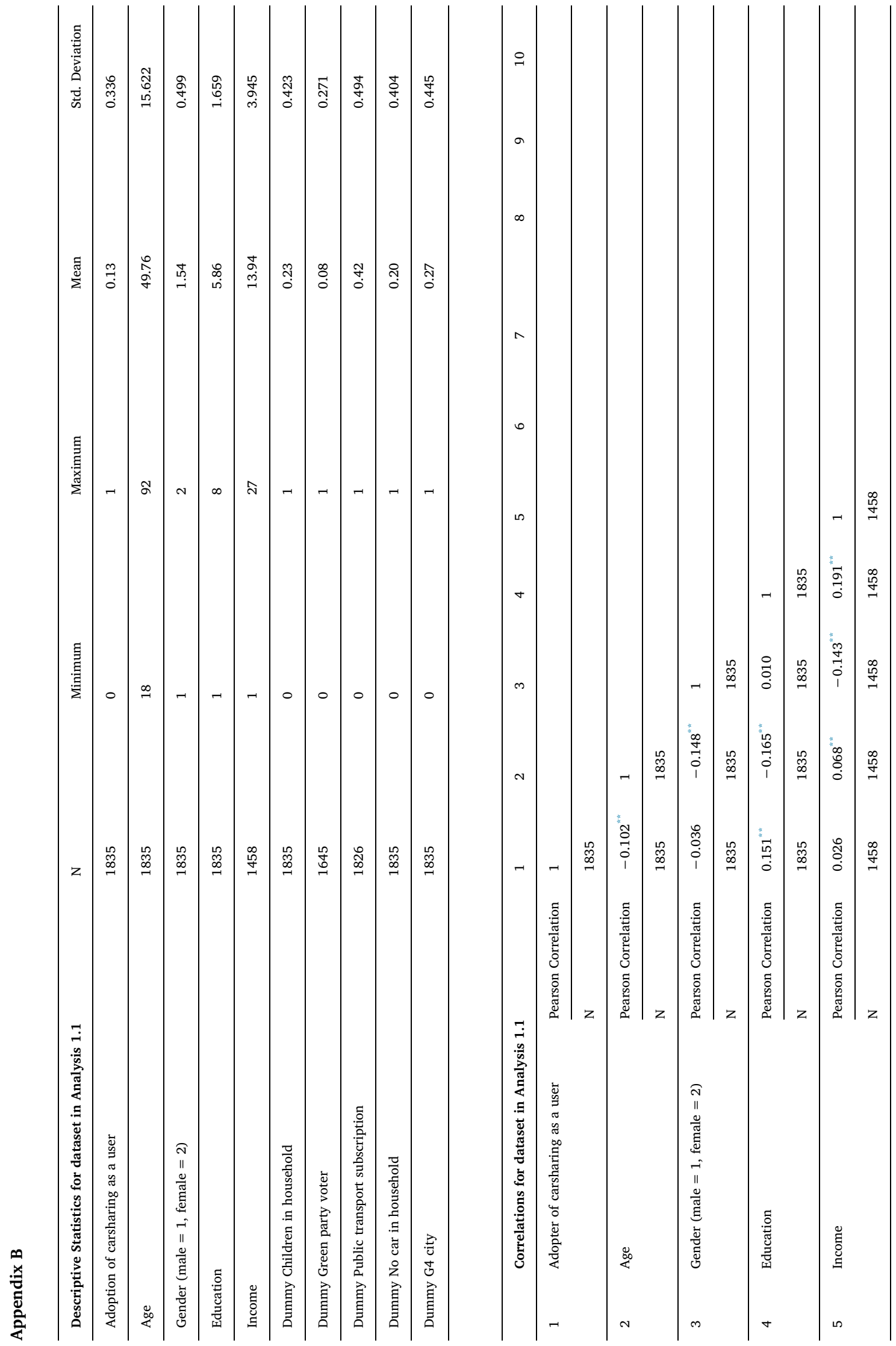




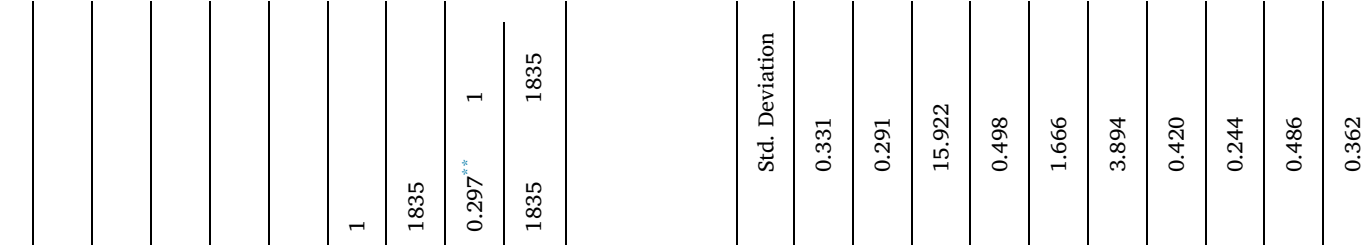

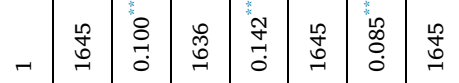

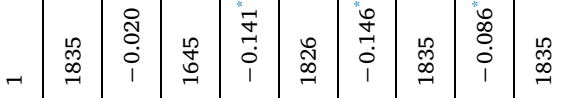

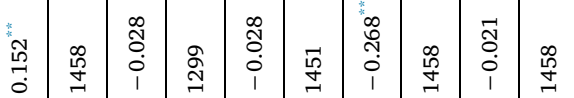

$$
\begin{aligned}
& \text { 范 }
\end{aligned}
$$

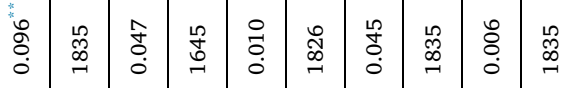

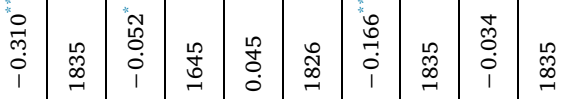

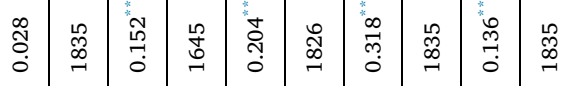

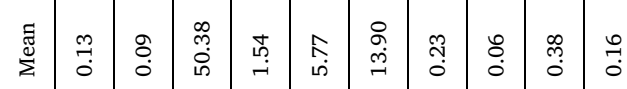

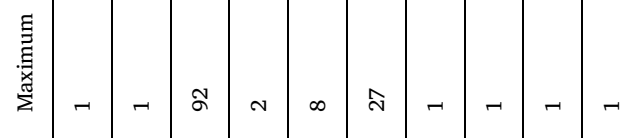

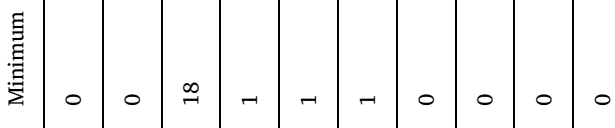

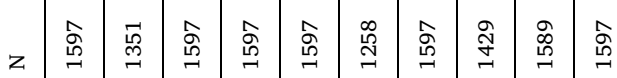

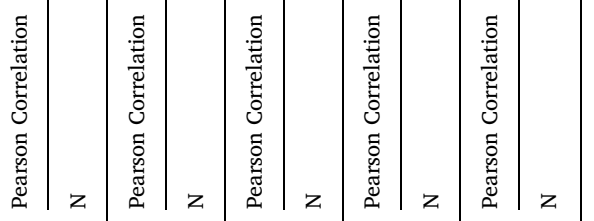

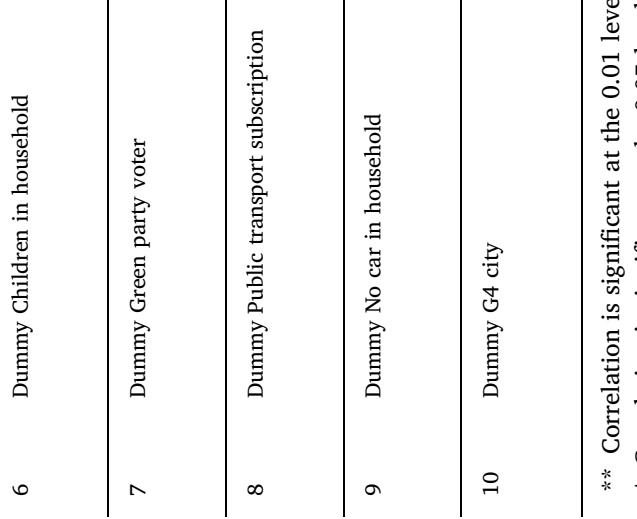

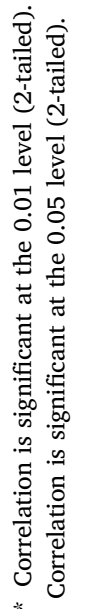

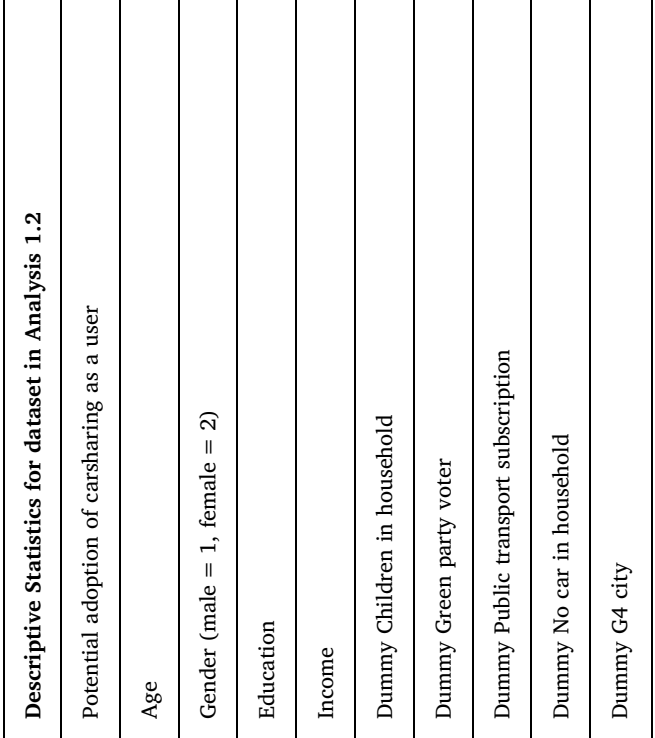




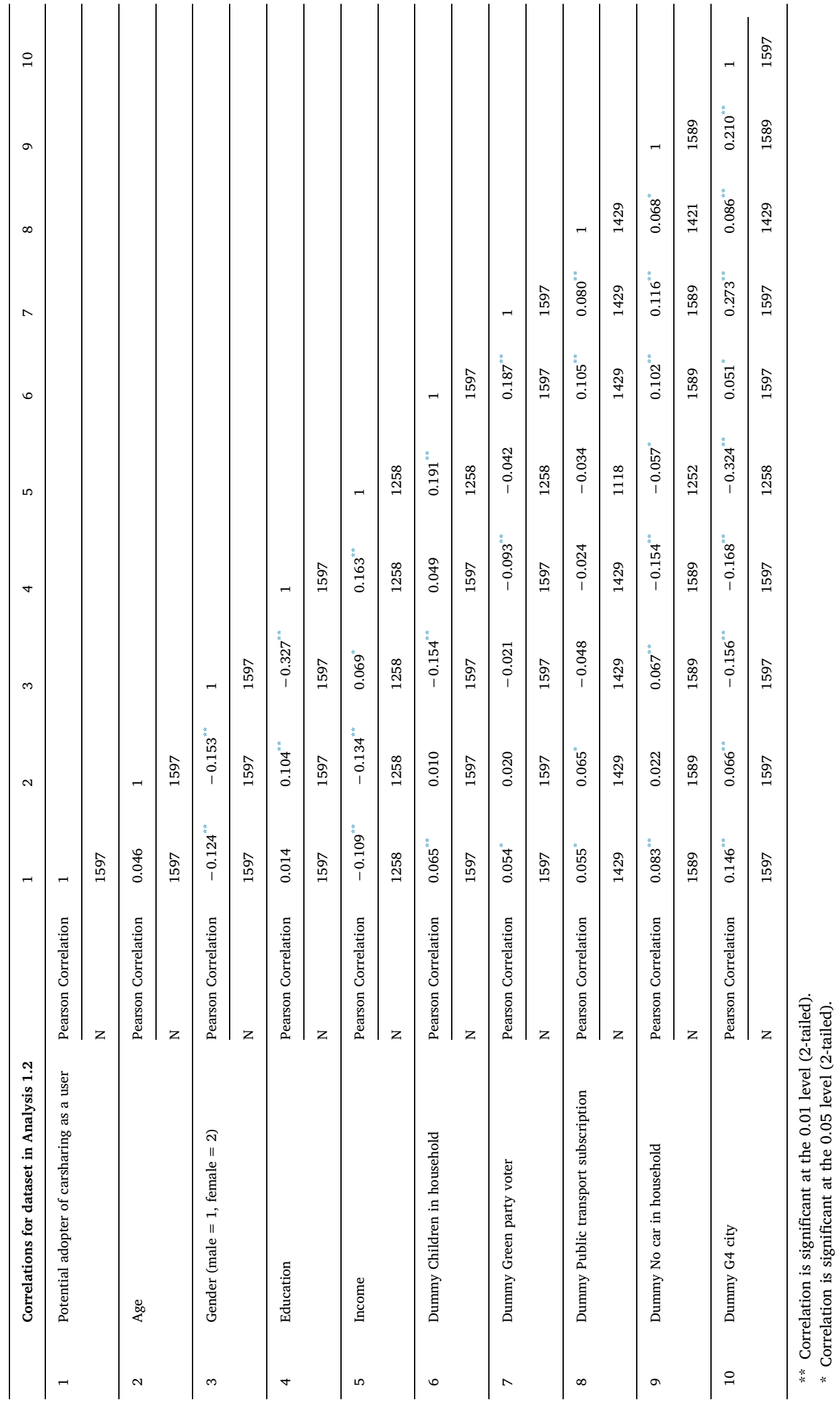




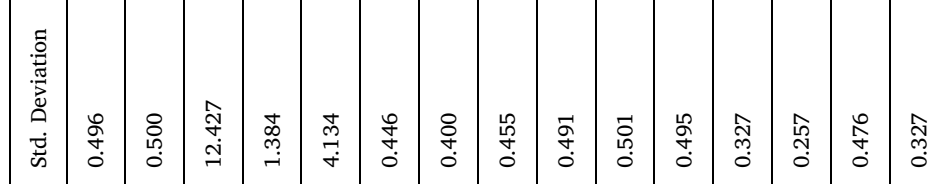

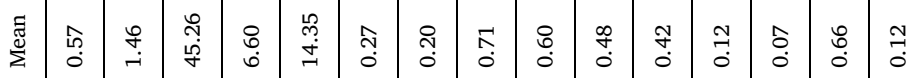

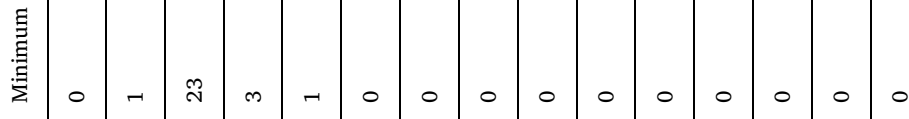

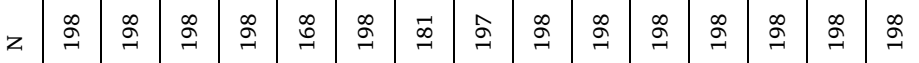

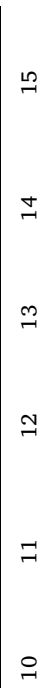

우

$\infty$

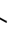

$\bullet$

เ

$+$

m

$-\quad \stackrel{\infty}{\circ}$

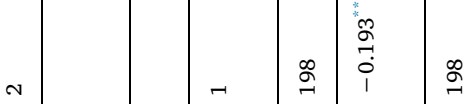

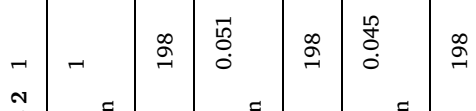

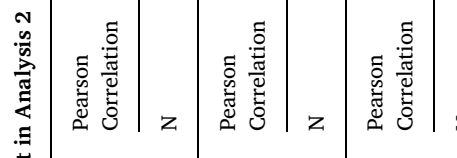

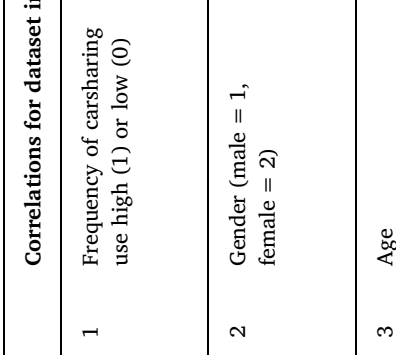




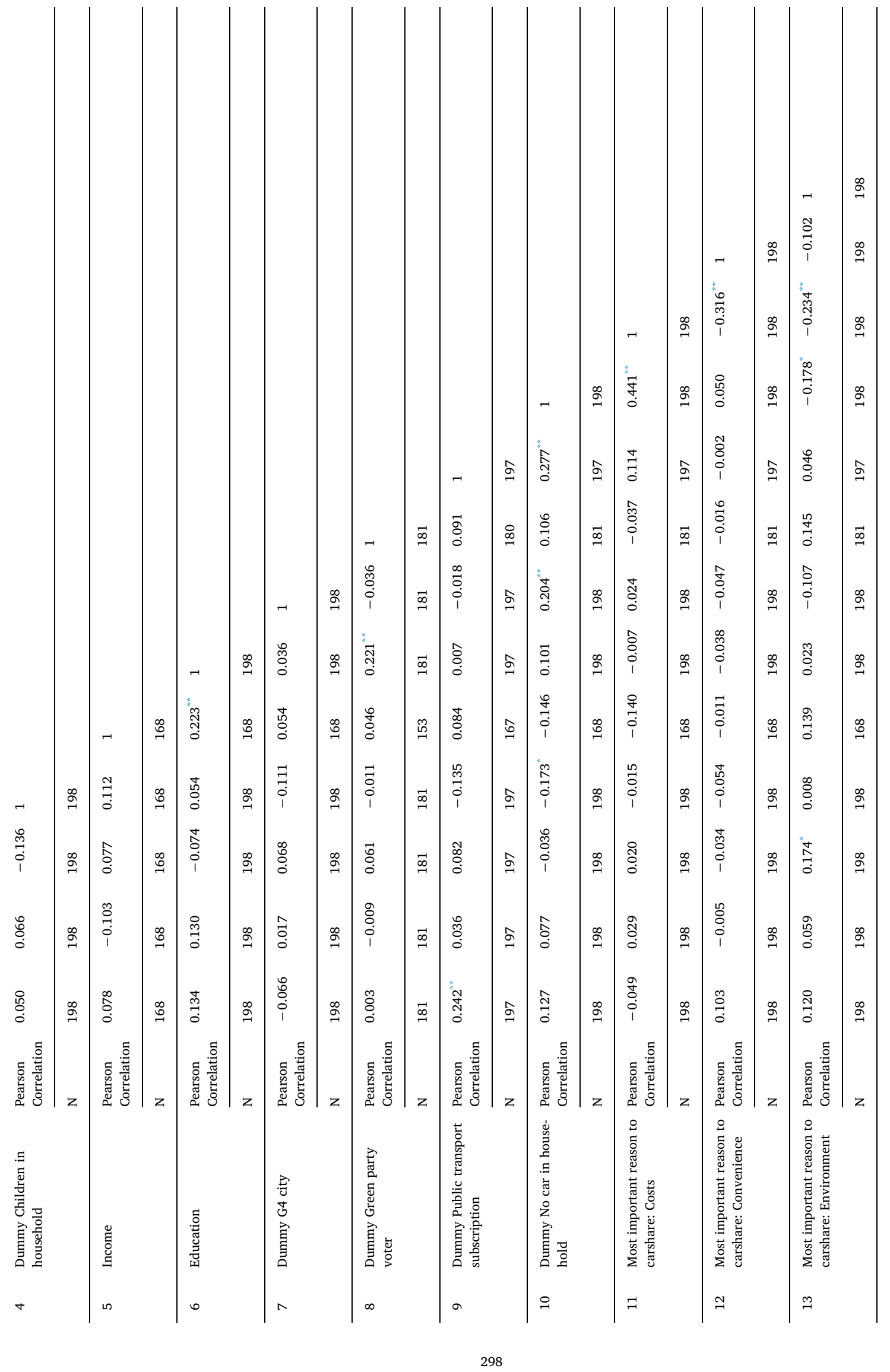




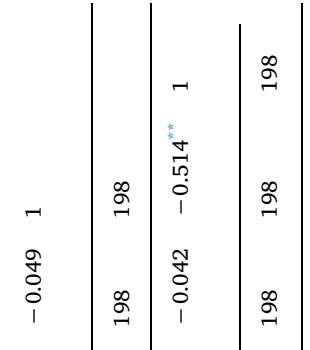

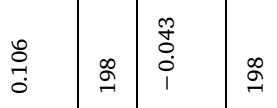

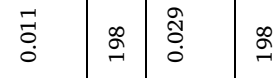

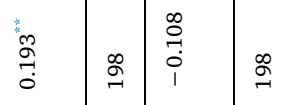

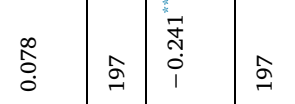

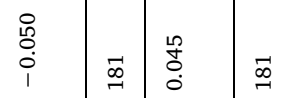

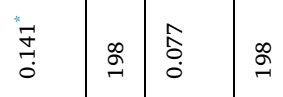

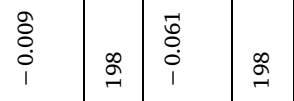

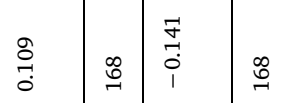

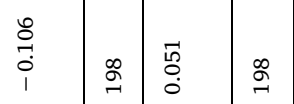

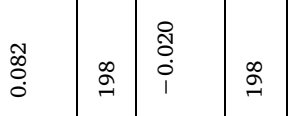

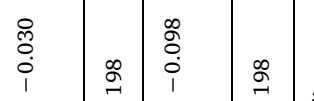

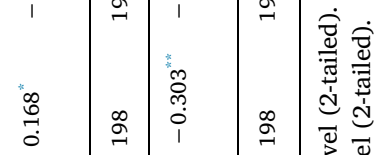

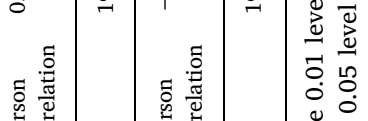

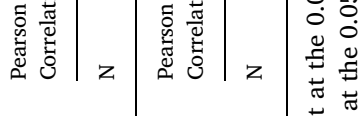

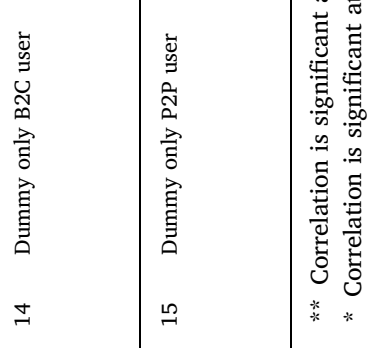

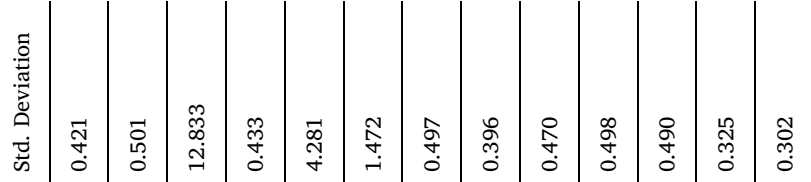

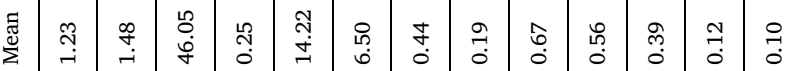
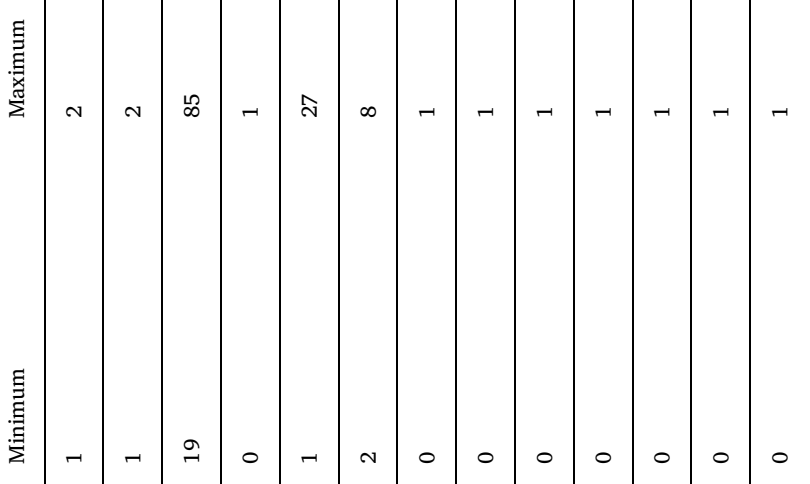

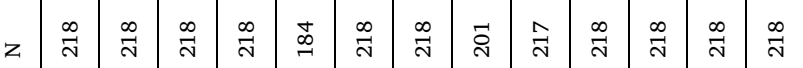

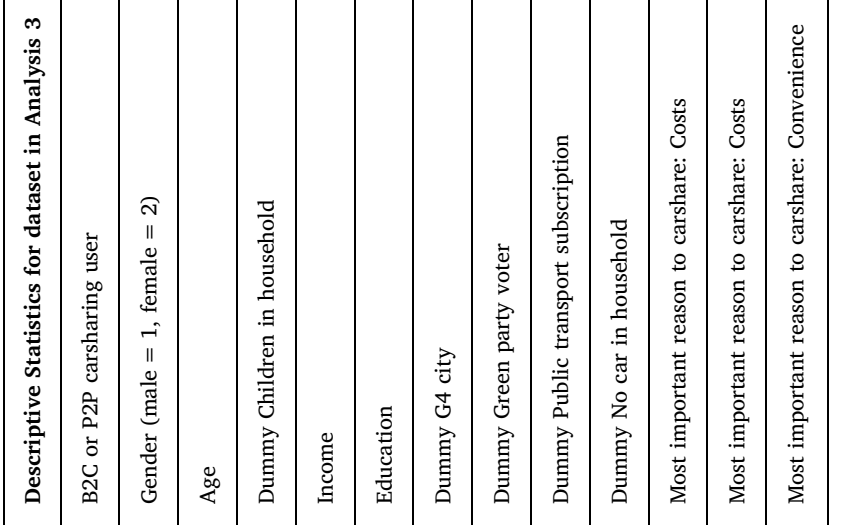




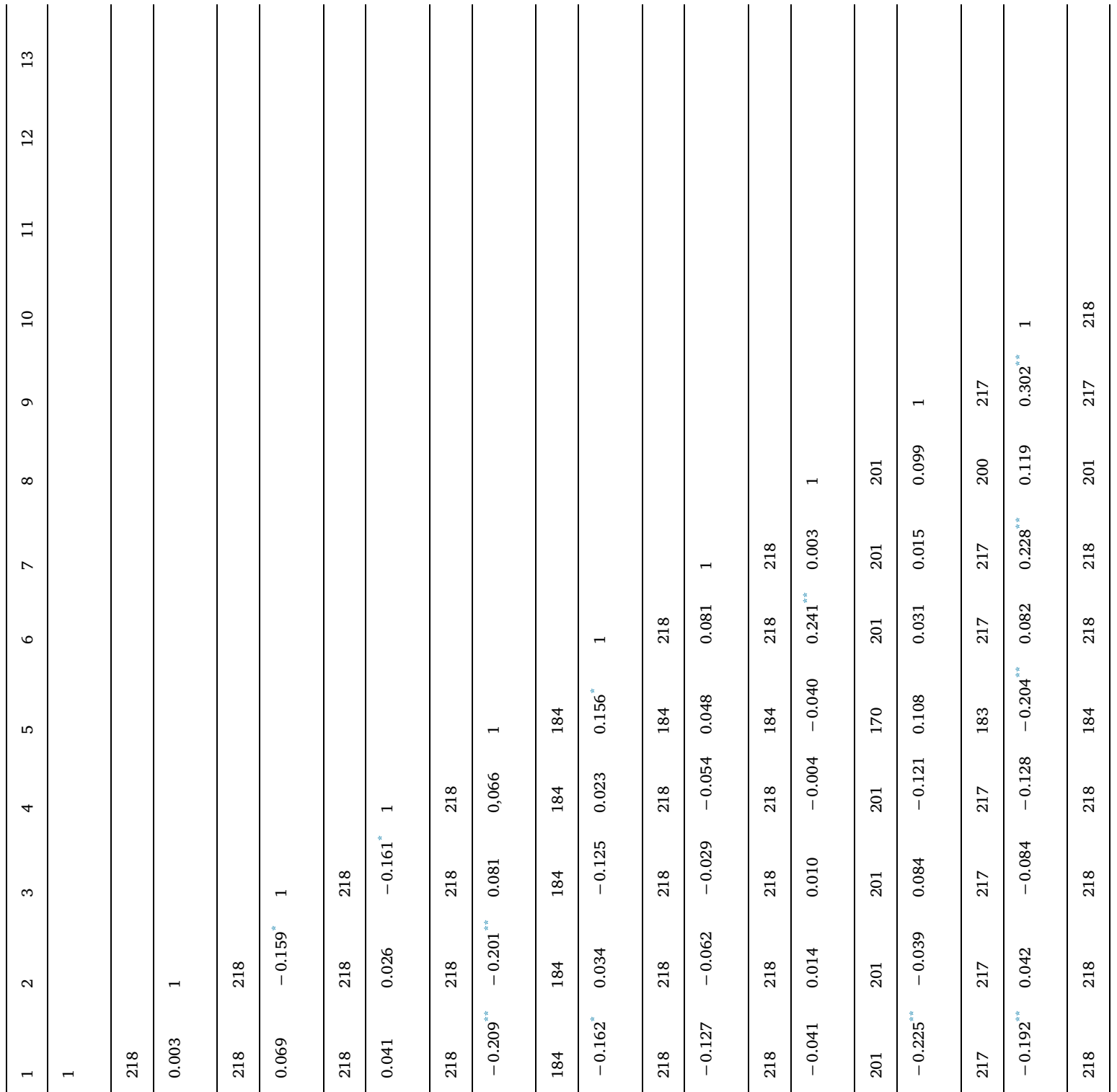
II
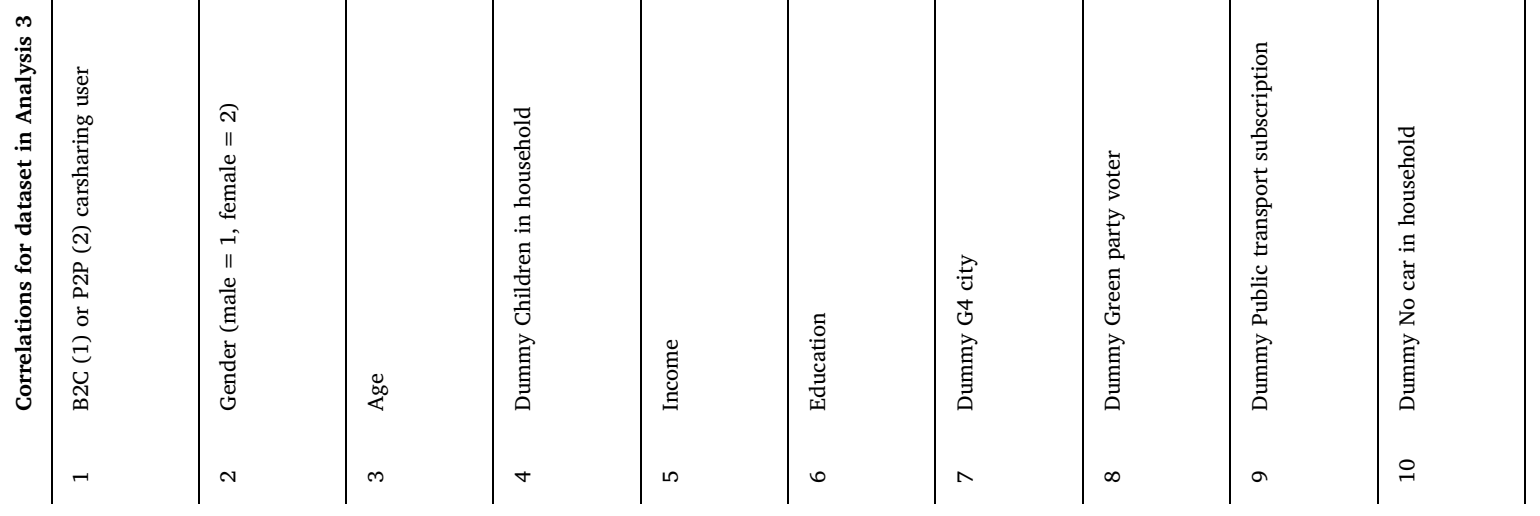


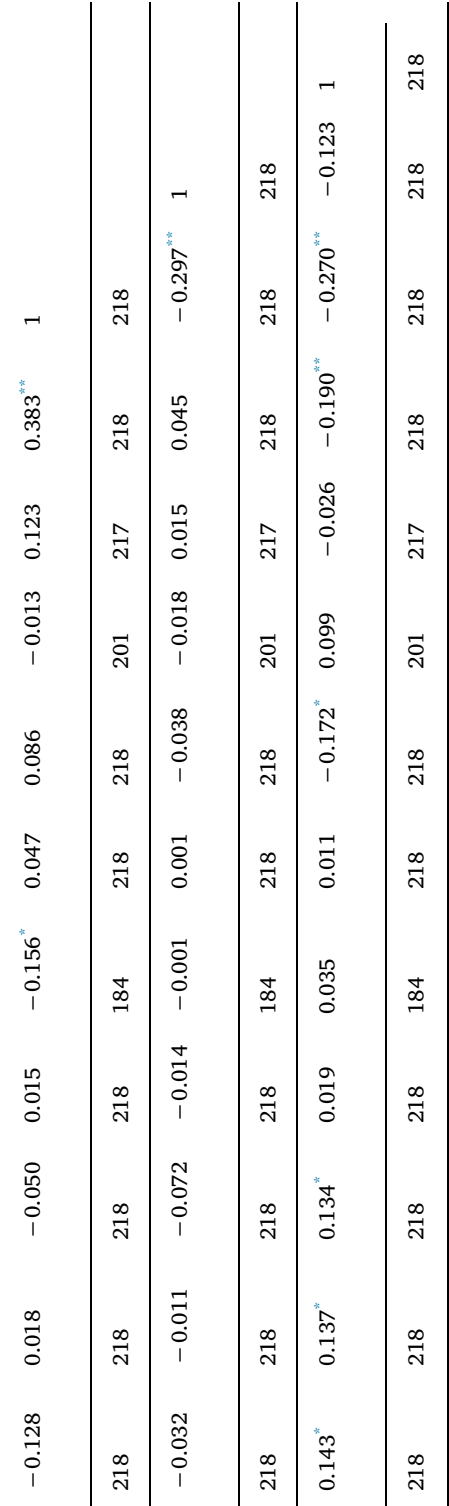

II

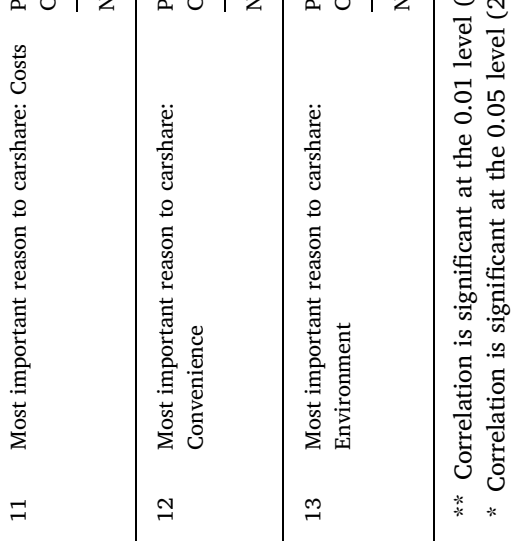

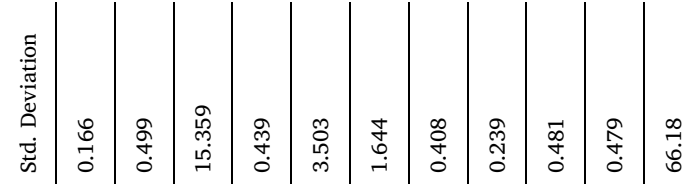

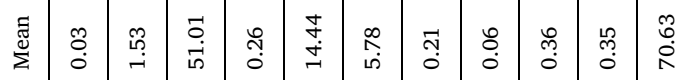
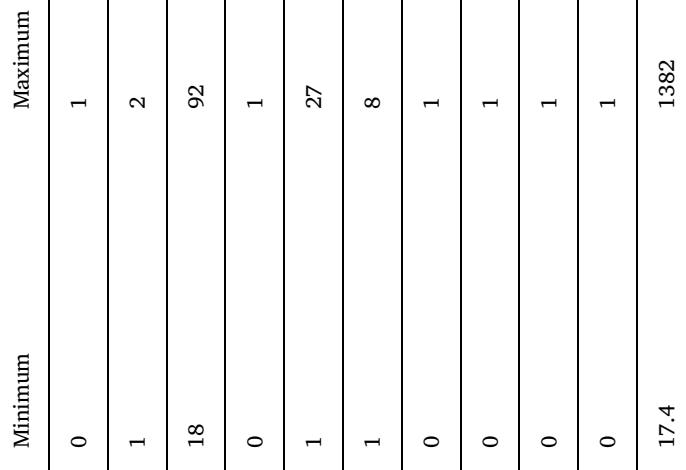

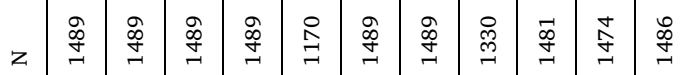

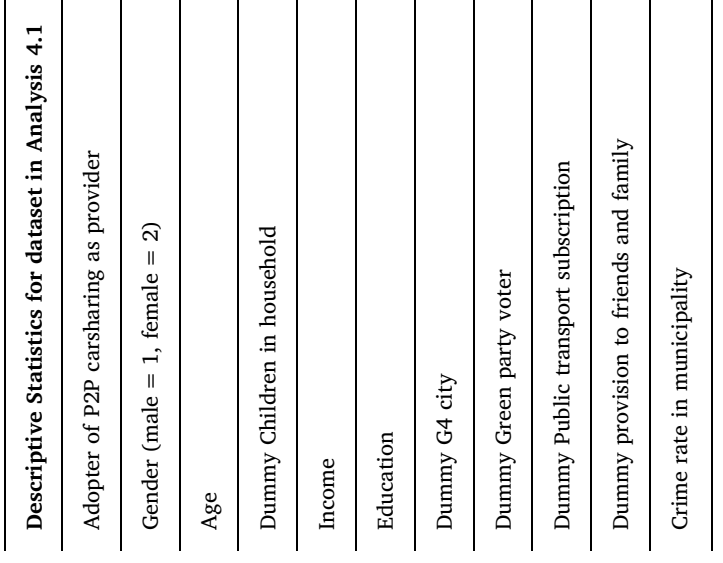




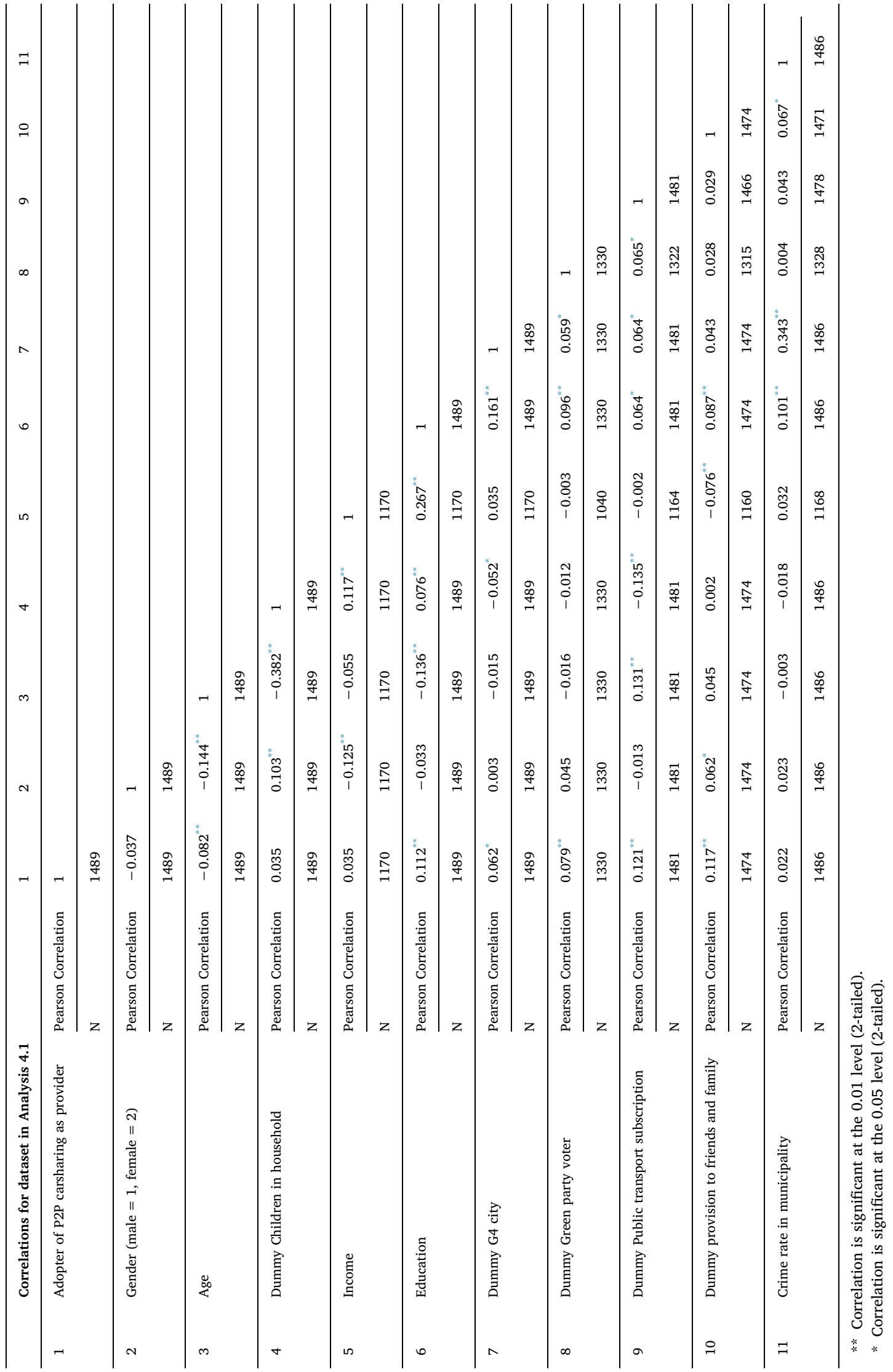




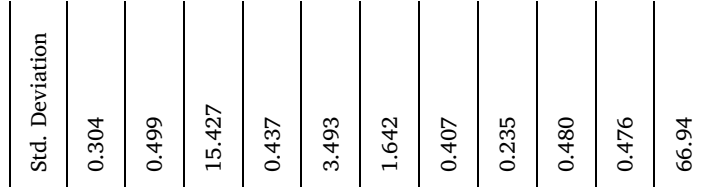

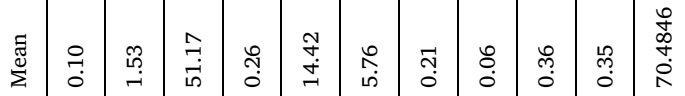

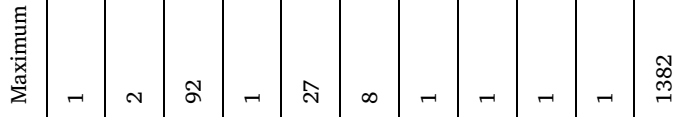

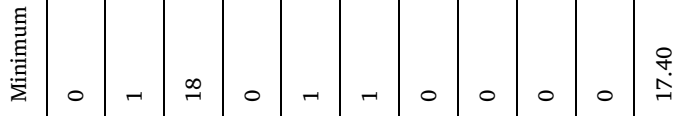

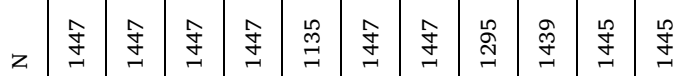

F

$a$

$\infty$

$\wedge$

$\bullet$

เ

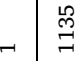

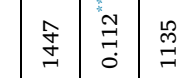

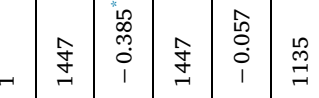

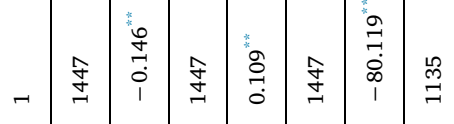

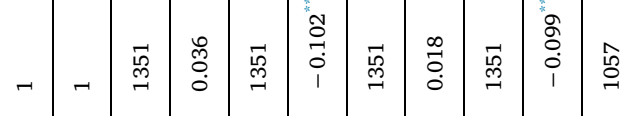

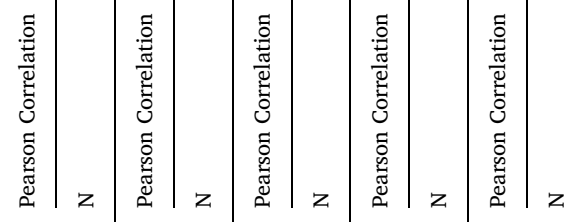

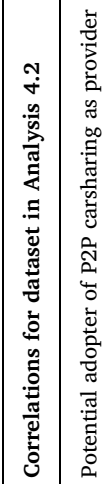

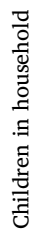

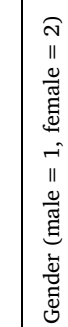
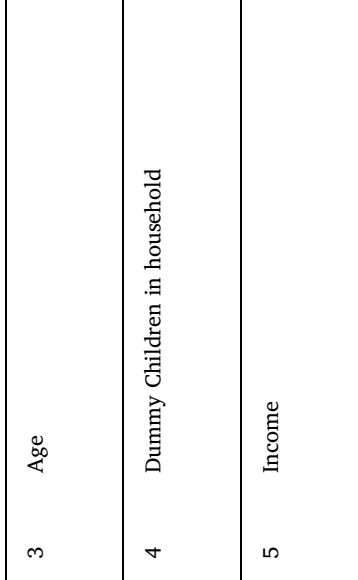

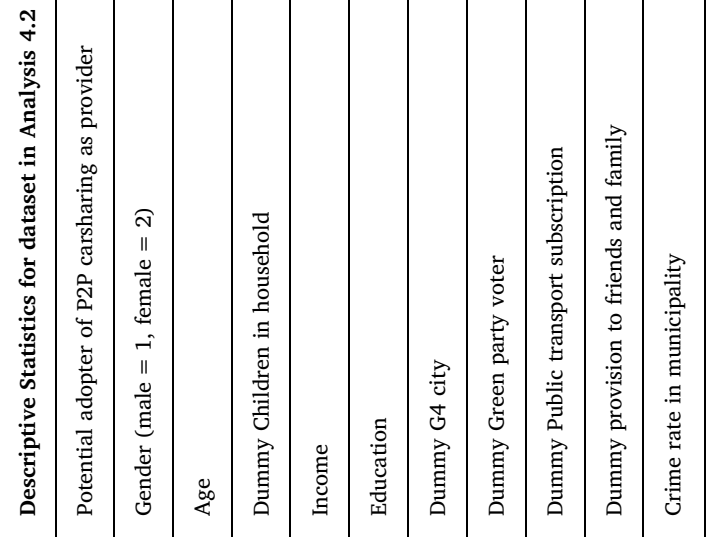




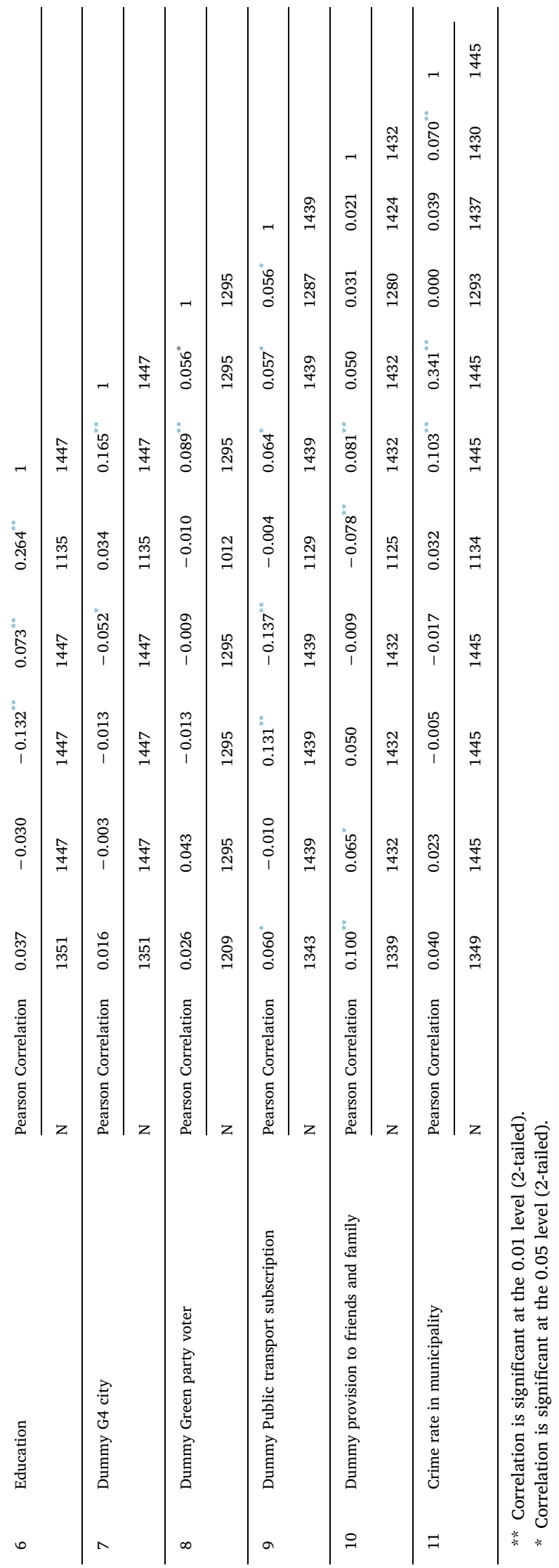




\section{References}

6t, 2014. One-way carsharing: which alternative to private cars? Executive Summary. Paris.

Autodelen.info, n.d. Ik heb een eigen auto [WWW Document]. URL https://autodelen.info/eigen-autodelen/ (accessed 10.15.18).

Ballús-Armet, I., Shaheen, S., Clonts, K., Weinzimmer, D., 2014. Peer-to-peer carsharing: exploring public perception and market characteristics in the San Francisco Bay area, California. Transp. Res. Rec. 2416, 27-36. https://doi.org/10.3141/2416-04.

Bardhi, F., Eckhardt, G.M., 2012. Access-based consumption: the case of car sharing. J. Consum. Res. 39. https://doi.org/10.1086/666376.

bcs, 2016. CarSharing fact sheet Nr. 2. Bundesverband CarSharing. Accessible at http://carsharing.de/sites/default/files/uploads/bcs factsheet_nr.2_0.pdf.

Becker, H., Ciari, F., Axhausen, K.W., 2017. Comparing car-sharing schemes in Switzerland: User groups and usage patterns. Transp. Res. Part A Policy Pract. 97, 17-29. https://doi.org/10.1016/j.tra.2017.01.004.

Benner, K., 2017. Airbnb Tries to Behave More Like a Hotel. New York Times.

Burkhardt, J., Millard-Ball, A., 2006. Who is attracted to carsharing? Transp. Res. Rec. J. Transp. Res. Board 1986, 98-105. https://doi.org/10.3141/1986-15.

Chen, T.D., Kockelman, K.M., 2016. Carsharing's life-cycle impacts on energy use and greenhouse gas emissions. Transp. Res. Part D Transp. Environ. 47, 276-284. https://doi.org/10.1016/j.trd.2016.05.012.

Clavel, R., Floriet, M., 2009. The increasing development of carsharing in France. European Transport Conference 2009, Leiden.

Clewlow, R.R., 2016. Carsharing and sustainable travel behavior: results from the San Francisco Bay Area. Transp. Policy 51, 158-164. https://doi.org/10.1016/j. tranpol.2016.01.013.

CROW, 2018. Stormachtige groei deelauto's houdt aan [WWW Document]. URL https://www.crow.nl/over-crow/nieuws/stormachtige-groei-deelautos-houdt-aan (accessed 10.15.18).

Daimler, 2008. Daimler startet Mobilitätskonzept für die Stadt: Car2go - so einfach wie mobiles Telefonieren [WWW Document]. URL http://media.daimler.com/ marsMediaSite/ko/de/9914253 (accessed 1.30.17).

Dias, F.F., Lavieri, P.S., Garikapati, V.M., Astroza, S., Pendyala, R.M., Bhat, C.R., 2017. A behavioral choice model of the use of car-sharing and ride-sourcing services. Transportation (Amsterdam) 1-17. https://doi.org/10.1007/s11116-017-9797-8.

Dill, J., Mcneil, N., Howland, S., 2017. Peer-To-Peer Carsharing: Short-Term Effects on Travel Behavior in Portland, OR. Transportation Research and Education Center, Portland, OR. https://doi.org/10.15760/trec.172.

Efthymiou, D., Antoniou, C., Waddell, P., 2013. Factors affecting the adoption of vehicle sharing systems by young drivers. Transp. Policy 29, 64-73. https://doi.org/ 10.1016/j.tranpol.2013.04.009.

Ehrenhard, M., Wijnhoven, F., van den Broek, T., Zinck Stagno, M., 2017. Unlocking how start-ups create business value with mobile applications: development of an app-enabled business innovation cycle. Technol. Forecast. Soc. Change 115, 26-36. https://doi.org/10.1016/j.techfore.2016.09.011.

Firnkorn, J., Müller, M., 2015. Free-floating electric carsharing-fleets in smart cities: the dawning of a post-private car era in urban environments? Environ. Sci. Policy 45, 30-40. https://doi.org/10.1016/j.envsci.2014.09.005.

Frenken, K., 2017. Political economies and environmental futures for the sharing economy. Philos. Trans. R. Soc. A Math. Phys. Eng. Sci. 375, 20160367. https://doi. org/10.1098/rsta.2016.0367.

Frenken, K., 2015. Towards a prospective transition framework. A co-evolutionary model of socio- technical transitions and an application to car sharing in The Netherlands. International Workshop on the Sharing Economy, Utrecht.

Giesel, F., Nobis, C., 2016. The impact of carsharing on car ownership in German cities. Transp. Res. Proc. 215-224. https://doi.org/10.1016/j.trpro.2016.12.082.

Habib, K.M.N., Morency, C., Islam, M.T., Grasset, V., 2012. Modelling users' behaviour of a carsharing program: application of a joint hazard and zero inflated dynamic ordered probability model. Transp. Res. Part A Policy Pract. 46, 241-254. https://doi.org/10.1016/j.tra.2011.09.019.

Hahn, C., 2015. Eine CarSharing-Zielgruppenanalyse der großen SrV-Vergleichsstädte. TU Dresden.

Jae-Hun, J., 2017. Motives for participating in sharing economy: intentions to use car sharing services. J. Distrib. Sci. 15, 21-26. https://doi.org/10.15722/jds.15.2. 201702.21.

Jorritsma, P., Harms, L., Berveling, J., 2015. Mijn auto, jouw auto, onze auto Deelautogebruik in Nederland: omvang, motieven en effecten. Den Haag.

Juschten, M., Ohnmacht, T., Thao, V.T., Gerike, R., Hössinger, R., 2017. Carsharing in Switzerland: identifying new markets by predicting membership based on data on supply and demand. Transportation (Amsterdam) 1-24. https://doi.org/10.1007/s11116-017-9818-7.

Katzev, R., 2003. Car sharing: a new approach to urban transportation problems. Anal. Soc. Iss. Public Policy 3, 65-86. https://doi.org/10.1111/j.1530-2415.2003. 00015.x.

Kawgan-Kagan, I., 2015. Early adopters of carsharing with and without BEVs with respect to gender preferences. Eur. Transp. Res. Rev. 7. https://doi.org/10.1007/ s12544-015-0183-3.

Kent, J., Dowling, R., Maalsen, S., 2017. Catalysts for transport transitions: bridging the gap between disruptions and change. J. Transp. Geogr. 60, 200-207. https:// doi.org/10.1016/j.jtrangeo.2017.03.013.

Kim, D., Ko, J., Park, Y., 2015. Factors affecting electric vehicle sharing program participantsâ€ ${ }^{\mathrm{TM}}$ attitudes about car ownership and program participation. Transp. Res. Part D 36, 96-106. https://doi.org/10.1016/j.trd.2015.02.009.

Knie, A., Lenz, B., Nobis, C., Nowack, F., Giesel, F., Blümel, H., 2016. Wirkung von E-Car Sharing Systemen auf Mobilität und Umwelt in urbanen Räumen (WiMobil) Gemeinsamer Abschlussbericht.

Koch, H., 2002. User Need Report. Moses (Mobility Services for Urban Sustainability) Project. Bremen.

Kopp, J., Gerike, R., Axhausen, K.W., 2013. Status quo and perspectives for CarSharing systems: the example of DriveNow. In: Hülsmann, F., Gerike, R., Roller, K. (Eds.), Strategies for Sustainable Mobilities - Opportunities and Challenges. Ashgate, Burlington, pp. 207-226.

Kortum, K., 2014. Driving smart: carsharing mode splits and trip frequencies. Transportation Research Board 93rd Annual Meeting, Washington DC. pp. No. 14-4009.

Lane, C., 2005. PhillyCarShare: First-year social and mobility impacts of carsharing in Philadelphia, Pennsylvania. Transp. Res. Rec. J. Transp. Res. Board 1927, 158-166. https://doi.org/10.3141/1927-18.

Le Vine, S., Polak, J., 2017. The impact of free-floating carsharing on car ownership: early-stage findings from London. Transp. Policy. https://doi.org/10.1016/j. tranpol.2017.02.004.

Martin, E., Shaheen, S., 2016. Impacts of car2go on vehicle ownership, modal shift, vehicle miles traveled, and greenhouse gas emissions: an analysis of five North American cities. Innovative Mobility, Berkeley, CA. USA.

Martin, E., Shaheen, S., Lidicker, J., 2010. Impact of carsharing on household vehicle holdings. Transp. Res. Rec. J. Transp. Res. Board 2143, 150-158. https://doi.org/ 10.3141/2143-19.

Martin, E.W., Shaheen, S.A., 2011. Greenhouse gas emission impacts of carsharing in North America. IEEE Trans. Intell. Transp. Syst. 12, 1074-1086. https://doi.org/ 10.1109/TITS.2011.2158539.

Meijkamp, R., 1998. Changing consumer behaviour through eco-efficient services: an empirical study of car sharing in the Netherlands. Bus. Strateg. Environ. 7, 234-244. https://doi.org/10.1002/(SICI)1099-0836(199809)7:4<234::AID-BSE159>3.0.CO;2-A.

Meijkamp, R.G., 2000. Changing Consumer Behaviour through Eco-Efficient Services - An Empirical Study on Car Sharing in the Netherlands. TU Delft.

Millard-Ball, A., Murray, G., Schure, J. Ter, Fox, C., Burkhardt, J., 2005. Car-Sharing: Where and how it Succeeds, Washington, D.C.

Moore, G.A., 1991. Crossing the Chasm: Marketing and Selling High-Tech Products to Mainstream Customers. HarperBusiness, New York, NY, USA.

Müller, J., Schmoeller, S., Giesel, F., 2015. Identifying users and use of (electric-) free-floating carsharing in Berlin and Munich. In: IEEE Conf. Intell. Transp. Syst. Proceedings, ITSC 2015-Octob, pp. 2568-2573. https://doi.org/10.1109/ITSC.2015.413.

Münzel, K., Boon, W., Frenken, K., Vaskelainen, T., 2018. Carsharing business models in Germany: characteristics, success and future prospects. Inf. Syst. E-bus. Manage. 16, 271-291. https://doi.org/10.1007/s10257-017-0355-x.

Nijland, H., van Meerkerk, J., 2017. Mobility and environmental impacts of car sharing in the Netherlands. Environ. Innov. Soc. Trans. https://doi.org/10.1016/j.eist. 2017.02.001.

Prieto, M., Baltas, G., Stan, V., 2017. Car sharing adoption intention in urban areas: What are the key sociodemographic drivers? Transp. Res. Part A Policy Pract. 101, 218-227. https://doi.org/10.1016/j.tra.2017.05.012.

Rifkin, J., 2015. The Zero Marginal Cost Society: The Internet Of Things, the Collaborative Commons, and the Eclipse Of Capitialism. Palgrave Macmillan.

Rijksoverheid, 2018. Meer deelauto's voor betere bereikbaarheid en schonere lucht [WWW Document]. Nieuwsbericht. URL https://www.rijksoverheid.nl/actueel/ 
nieuws /2018/10/04/meer-deelauto's-voor-betere-bereikbaarheid-en-schonere-lucht (accessed 10.15.18).

Rijksoverheid, 2015. Over drie jaar honderdduizend deelauto's in Nederland [WWW Document]. Nieuwsbericht. URL https://www.rijksoverheid.nl/actueel/nieuws/ 2015/06/03/over-drie-jaar-honderdduizend-deelauto-s-in-nederland.

Rogers, E.M., 2003. Diffusion of Innovation, fifth ed. Free Press, New York, NY, USA.

Schreier, H., Grimm, C., Kurz, U., Schwieger, D.B., Keßler, S., Möser, D.G., 2018. Analysis of the impacts of car-sharing in Bremen, Germany.

Shaheen, S., Cohen, A., 2007. Growth in worldwide carsharing: an international comparison. Transp. Res. Rec. J. Transp. Res. Board 1992, 81-89. https://doi.org/10. 3141/1992-10.

Shaheen, S., Cohen, A., Zohdy, I., 2016. Shared Mobility: Current Practices and Guiding Principles, FHWA-HOP-16-022 2.

Shaheen, S., Cohen, A., Zohdy, I., Kock, B., 2016. Smartphone Applications to Influence Travel Choices - Practices and Policies. Washington, DC. https://doi.org/10. 1017/CBO9781107415324.004.

Shaheen, S., Martin, E., Bansal, A., 2018. Peer-To-Peer (P2P) carsharing: understanding early markets. Soc. Dyn. Behav. Imp. https://doi.org/10.7922/G2FN14BD.

Shaheen, S., Sperling, D., Wagner, C., 1998. Carsharing in Europe and North America: past, present, and future. Transp. Q. 52, 35-52. https://doi.org/10.1068/ a201285.

Shaheen, S., Wipyewski, K., Rodier, C., Novick, L., Meyn, M.A., Wright, J., 2004. Carlink II: a commuter carsharing pilot program final report, California PATH Research Report UCB-ITS-PRR-2004-23. Berkeley.

Shaheen, S.A., 1999. Dynamics in Behavioral Adaptation to a Transportation Innovation: A Case Study of Carlink-A Smart Carsharing System California PATH Research Report. Berkeley.

Shaheen, S.A., Mallery, M.A., Kingsley, K.J., 2012. Personal vehicle sharing services in North America. Res. Transp. Bus. Manage. https://doi.org/10.1016/j.rtbm. 2012.04.005.

SmartAgent, 2011. Utrechts Autodelen : perceptie en praktijk.

SnappCar, 2018. Autodelen zonder sleuteloverdracht met SnappCar Keyless [WWW Document]. SnappCar Blog. URL https://blog.snappcar.nl/2018/05/31/snappcardirect/ (accessed 10.15.18).

Sperling, D., 2018. Three Revolutions. Steering Automated, Shared and Electric Vehicles to a Better Future. Island Press.

Steer Davies Gleave, 2017. Carplus Annual Survey of Car Clubs 2016/17 Scotland. Leeds.

Steer Davies Gleave, 2017. Carplus Annual Survey of Car Clubs 2016/17 London. Leeds.

Steer Davies Gleave, 2016. Carplus Annual Survey of Car Clubs 2015/16 England and Wales (excluding London). Leeds.

Steininger, K., Vogl, C., Zettl, R., 1996. Car-sharing organizations. Transp. Policy 3, 177-185. https://doi.org/10.1016/S0967-070X(96)00024-8.

Truffer, B., 2003. User-led innovation processes: the development of professional car sharing by environmentally concerned citizens. Innov. Eur. J. Soc. Sci. Res. 16, 139-154. https://doi.org/10.1080/13511610304517.

Wappelhorst, S., Graff, A., Steiner, J., Hinkeldein, D., 2013. New carsharing offers and customer groups: implications for a growing and diversifying market. European Transport Conference.

Wilhelms, M.-P., Henkel, S., Merfeld, K., 2017a. You are what you share: understanding participation motives in peer-to-peer carsharing. In: Meyer, G., Shaheen, S. (Eds.), Disrupting Mobility - Impacts of Sharing Economy and Innovative Transportation on Cities, Lecture Notes in Mobility. Springer International Publishing, Cham, pp. 105-120. https://doi.org/10.1007/978-3-319-51602-8.

Wilhelms, M.-P., Merfeld, K., Henkel, S., 2017b. Yours, mine, and ours: a user-centric analysis of opportunities and challenges in peer-to-peer asset sharing. Bus. Horiz. https://doi.org/10.1016/j.bushor.2017.07.004. 